\title{
Lotte Sommerer* and Andreas Baumann Of absent mothers, strong sisters and peculiar daughters: The constructional network of English NPN constructions
}

\author{
https://doi.org/10.1515/cog-2020-0013 \\ Received February 8, 2020; accepted December 5, 2020; \\ published online January 27,2021
}

Abstract: This paper analyzes symmetric NPN constructions (e.g., day to day, face to face, step by step) qualitatively and quantitatively by examining data from the Corpus of Contemporary American English (Davies, Mark. 2008-. The Corpus of Contemporary American English (COCA): 570 million words, 1990-present. http://corpus.byu.edu/coca/). The constructions' frequency and productivity, as well as their semantics and extension potential (i.e., modification, complementation) is investigated (e.g., by conducting collostructional analysis). In terms of theoretical modeling, the paper takes a Usage-based, Cognitive Construction Grammar approach (UCCxG) and sketches the constructional network of this constructional family, postulating various constructional templates on different levels of specificity - among others - the existence of the following subtypes $\left[\mathrm{CN}_{\mathrm{sg} \text {,time }}{ }^{\mathrm{i}} \text { after } \mathrm{CN}_{\mathrm{sg} \text {,time }}{ }^{\mathrm{i}}\right]_{\mathrm{Cx}}$ (e.g., day after day, night after night), $\left[\mathrm{CN}_{\mathrm{sg}, \text { measurement }}^{\mathrm{i}} \text { by } \mathrm{CN}_{\mathrm{sg} \text {,measurement }}{ }^{\mathrm{i}}\right]_{\mathrm{Cx}}$ (e.g., inch by inch, step by step) or $\left[\mathrm{CN}_{\mathrm{sg} \text {,bodypart }}{ }^{\mathrm{i}} \text { to } \mathrm{CN}_{\mathrm{sg} \text {, bodypart }}{ }^{\mathrm{i}}\right]_{\mathrm{Cx}}$ (e.g., skin to skin, shoulder to shoulder). We show how these templates are vertically and horizontally connected to each other. Ultimately, we argue that in a usage-based model which strives for cognitive plausibility it is not always feasible to postulate the entrenchment of an abstract overarching schema (i.e., a 'mothernode') like $\left[\mathrm{CN}^{\mathrm{i}} \mathrm{P} \mathrm{CN}{ }^{\mathrm{i}}\right]_{\mathrm{Cx}}$ or even $[\mathrm{N} \mathrm{P} \mathrm{N}]_{\mathrm{Cx}}$ high up in the network. It is unlikely that speakers abstract such a general schema in a bottom-up acquisition process for this family. Rather, the NPN group is a constructional family characterized by many sister ties and by the absence of mother nodes from which information can be inherited.

Keywords: abstract schemas; binominals; collostructional analysis; NPN constructions; parent and peer relations; Usage-based Cognitive Construction Grammar

\footnotetext{
*Corresponding author: Lotte Sommerer, Department of English, University of Vienna, Spitalgasse 2-4, AAKH Hof 8.3, Vienna, 1090, Austria, E-mail: lotte.sommerer@univie.ac.at Andreas Baumann, Department of English Studies, Universität Wien, Vienna, Austria, E-mail: andreas.baumann@univie.ac.at
} 


\section{Introduction}

This paper analyses symmetric NPNs in Present Day American English. In these constructions, one finds two identical, singular count nouns (CN) conjoined by a preposition:

(1) Night after night, my dreams took me to a cold abyss. (2014, FIC, FantasySciFi)

(2) We know she will indeed meet Jon Snow and Tyrion face to face. (2017, MAG, Mashable)

(3) We met one robot who works side by side with people. (2017, SPOK, CBS: Tis Morning)

(4) Thus, generation upon generation has rediscovered fire. (1995, ACAD, African Arts)

The constructions' form-function mismatch make them an interesting target for linguistic analysis. It will be argued that a usage-based, constructional approach ${ }^{1}$ is the most fruitful one to analyze these constructions with their reduced referentiality, their apparent frozenness, their semi-idiomaticity, their semi-productivity and their non-canonical syntactic structure (see section 2 for characteristic features of the construction). By offering a constructional sketch of the NPN family, the paper aims to further develop the analysis proposed by Jackendoff (2008). Next to other questions, this paper primarily discusses when it is warranted to postulate the existence of a particular construction; especially when it is feasible to assume very abstract schematic templates 'high up' in the network.

Regarding the empirical analysis, the paper presents an extensive corpus study focusing on NPNs with temporal nouns $\left[\mathrm{CN}_{\mathrm{sg} \text {,time }}{ }^{\mathrm{i}} \mathrm{P} \mathrm{CN}_{\mathrm{sg}, \text { time }}{ }_{\mathrm{Cx}}{ }^{2}\right.$ using data from the online version of the Corpus of Contemporary American English (COCA, Davis 2008-). The paper investigates the construction's frequency, productivity as well as its limited extension potential (e.g., modification, complementation). Questions to be addressed include which preposition is the most productive and which singular common nouns are primarily attracted to the construction. A collexeme analysis will reveal which nouns and prepositions are particularly

1 The paper subscribes to a Usage-based Cognitive Construction Grammar model (henceforth UCCxG) (Diessel 2015, 2019; Divjak 2019; Ellis et al. 2016; Goldberg 2003, 2006, 2019; Hilpert 2014; Hilpert and Diessel 2016; Sommerer 2018; Sommerer and Smirnova 2020).

2 This annotation specifies that the noun has to be count $(\mathrm{CN})$, singular (sg), identical (i) and temporal (time). 
attracted to the construction (Stefanowitsch 2006, 2013; Stefanowitsch and Gries 2003). ${ }^{3}$

Although the symmetric NPN construction often recruits other nouns as well (body parts, measure nouns, ...), several pilot queries have revealed that the examples with temporal nouns are the most frequent ones in terms of token frequency and thus limiting ourselves to $\left[\mathrm{CN}_{\mathrm{sg} \text {,time }}{ }^{\mathrm{i}} \mathrm{P} \mathrm{CN}_{\mathrm{sg} \text {,time }}{ }^{\mathrm{i}}\right]_{\mathrm{Cx}}$ was considered a feasible start for a quantitative analysis. ${ }^{4}$ Nevertheless, the nature and constructional status of other subtypes like inch by inch or student after student will be discussed from a theoretical point of view in section 4 of the paper.

UCCxG is probably the "fastest growing linguistic and interdisciplinary approach to language" (Goldberg 2013: 30; see section 4 for more details on its basic tenets). Although Construction Grammar as a framework is extremely popular and spreading fast, many open questions like the ones mentioned above are pending. We believe that the empirical quantitative and qualitative analysis of NPN constructions can help tackle these unresolved issues in constructional modeling. Before outlining the structure of the paper, we would like to use the rest of this introduction to discuss a specific NPN example in order to shed more light on the unresolved issues at hand.

If we, disciples of $\mathrm{CxG}$, come across the concrete utterance day to day, we might be tempted - based on its non-canonical formal structure - to analyze it as a construct which is licensed by the fully-specified, frozen idiomatic construction [day to day $]_{\mathrm{Cx}}$. However, similar strings like night to night, month to month, or season to season exist. This suggests that some constructs might rather be licensed by a more abstract construction, namely $\left[\mathrm{CN}_{\mathrm{sg} \text {,time }}{ }^{\mathrm{i}} \text { to } \mathrm{CN}_{\mathrm{sg} \text {,time }}{ }^{\mathrm{i}}\right]_{\mathrm{Cx}}$ with a specified preposition to and two open noun slots in which various temporal nouns get reduplicated. However, as was shown in examples (1)-(4), not only the nouns but also the prepositions vary. Constructs like day after day or day by day make it possible to postulate other semi-specific templates like $\left[\mathrm{CN}_{\mathrm{sg} \text {,time }}{ }^{\mathrm{i}} \text { after } \mathrm{CN}_{\mathrm{sg} \text {,time }}{ }^{\mathrm{i}}\right]_{\mathrm{Cx}}$ or $\left[\mathrm{CN}_{\mathrm{sg}} \text {, time }{ }^{\mathrm{i}} \text { by } \mathrm{CN}_{\mathrm{sg} \text {,time }}{ }^{\mathrm{i}}\right]_{\mathrm{Cx}}$. It is also possible that the attested constructs are successfully licensed by an even more abstract mother construction $\left[\mathrm{CN}_{\mathrm{sg} \text {,time }}{ }^{\mathrm{i}} \mathrm{P}\right.$ $\left.\mathrm{CN}_{\mathrm{sg} \text {,time }}{ }^{\mathrm{i}}\right]_{\mathrm{Cx}}$ with an 'open' prepositional slot. If such a construction exists, what is its meaning/function?

Note that not only temporal nouns are used; we find strings like step by step, room upon room, dollar for dollar or shoulder to shoulder. This automatically begs the question whether all of these constructions are licensed by a $\left[\mathrm{CN}_{\mathrm{sg}}{ }^{\mathrm{i}} \mathrm{P} \mathrm{CN} \mathrm{CN}_{\mathrm{sg}}{ }^{\mathrm{i}}\right]_{\mathrm{Cx}}$ template in which the semantic nature of the common noun is not specified at all.

3 We would like to thank Ozan Mustafa for his help with the empirical data analysis (data extraction and tagging).

4 See section 3 for more details on the methodological set up (and its limitations). 
On top of that, corpus work reveals that a handful of examples with plural common nouns and mass nouns exists. ${ }^{5}$ Does that mean that the restriction to singular nouns does not hold and that we have to postulate a (less-specified) $\left[\mathrm{N}^{\mathrm{i}} \mathrm{P} \mathrm{N}^{\mathrm{i}}\right]_{\mathrm{Cx}}$ template?

Next, NPNs often occur together with the preposition from like in from coast to coast or from day to day, which are similar to from Salzburg to Vienna or from May to June. Does that imply that the underlying construction is $\left[\text { (from) } \mathrm{CN}_{\mathrm{sg}}{ }^{\mathrm{i}} \text { to } \mathrm{CN}_{\mathrm{sg}}{ }^{\mathrm{i}}\right]_{\mathrm{Cx}}$ with an optional from, or is this a different construction, namely [from $\mathrm{X}$ to $\mathrm{Y}]_{\mathrm{Cx}}$ ?

Moreover, we find examples like day after day of suffering, hour by precious hour or disastrous season after disastrous season with modification and complementation (see section 2.1). Do constructions like this suggest the existence of a much more complex construction with optional modification slots:

$$
\left.\left[\left(\mathrm{ADJ}_{\mathrm{mod}}\right) \mathrm{CN}_{\mathrm{sg} \text {,time }}{ }^{\mathrm{i}} \mathrm{P}\left(\mathrm{ADJ} \mathrm{mod}_{\mathrm{mod}}\right) \mathrm{CN}_{\mathrm{sg}, \text { time }}{ }^{\mathrm{i}} \text { (of } \mathrm{X}_{\mathrm{compl}}\right)\right]_{\mathrm{Cx}}
$$

Finally, some researchers also classify strings like mind over matter, or hand over fist as NPNs (Jackendoff and Audring 2019: 237; Payne and Huddleston 1985: 280); in such cases the nouns are no longer identical. ${ }^{6}$ Does that suggest the existence of a highly abstract $[\mathrm{N} \mathrm{P} \mathrm{N}]_{\mathrm{Cx}}$ construction? If yes, what kind of meaning/function would we assign to this very general formal constructional schema? As can be seen, the list of open questions is rather long; still, this paper aims to shed light on some of them.

Based on our empirical findings, we will argue that in many cases it is absolutely necessary to postulate the existence of fully-specified, fixed constructions due to their very specific idiomatic nature (e.g., [day to day $]_{\mathrm{Cx}}$, [eye to eye $]_{\mathrm{Cx}}$, [step by step $]_{\mathrm{Cx}}$ ). In that sense we consider them to be 'peculiar daughters' with some idiosyncratic behavior. After all, in Construction Grammar, formal and semantic peculiarity warrants constructional status (Croft and Cruse 2004: 263).

We will also postulate the existence of several semi-specified constructional schemas, for example:

$$
\begin{aligned}
& \text { a. }\left[\mathrm{CN}_{\mathrm{sg}, \text { time }}{ }^{\mathrm{i}} \text { after } \mathrm{CN}_{\mathrm{sg}, \mathrm{time}}{ }^{\mathrm{i}}\right]_{\mathrm{Cx}} \text { (hour after hour, day after day, year after } \\
& \text { year, ...) } \\
& \text { b. }\left[\mathrm{CN}_{\mathrm{sg}, \text { time }}^{\mathrm{i}} \text { to } \mathrm{CN}_{\mathrm{sg}, \mathrm{time}}{ }^{\mathrm{i}}\right]_{\mathrm{Cx}} \text { (season to season, day to day, ...) }
\end{aligned}
$$

Additionally, we propose that other NPN templates exist, for example

5 E.g., hours after hours, skin to skin.

6 As the identity of the two nouns is a prerequisite for the emerging semantic peculiarities of the NPN subtypes (Travis 2001, 2003), all the examples in which the CNs are not identical are not considered instantiations of the symmetric reduplicating NPN type but are assumed to be licensed by other (related) templates (see sections 2.1 and 4.2 for details). 
a. $\left[\mathrm{CN}_{\mathrm{sg} \text {,measurement }}{ }^{\mathrm{i}} \text { by } \mathrm{CN}_{\mathrm{sg} \text {,measurement }}{ }^{\mathrm{i}}\right]_{\mathrm{Cx}}$ (inch by inch, layer by layer)

b. $\left[\mathrm{CN}_{\mathrm{sg} \text {, bodypart }}^{\mathrm{i}} \text { to } \mathrm{CN}_{\mathrm{sg} \text {, bodypart }}{ }^{\mathrm{i}}\right]_{\mathrm{Cx}}$ (back to back, shoulder to shoulder)

c. $\left[\mathrm{CN}_{\mathrm{sg} \text {,entity }}^{\mathrm{i}} \text { after } \mathrm{CN}_{\mathrm{sg}, \text { entity }}{ }^{\mathrm{i}}\right]_{\mathrm{Cx}}$ (student after student, government after government)

These other templates account for the fact that measure nouns or body parts are often juxtaposed as slot fillers in the construction. The different meanings of the various templates will be discussed. Depending on the chosen preposition and type of noun, the constructions can express various meanings like succession, juxtaposition or transition in time and space (Haïk 2009; Jackendoff 2008, 2013; Kim and Sells 2015; Zwarts 2013).

Finally, we will also sketch the constructional network of this constructional family discussing the vertical and horizontal connections between the subtypes. We will try to drive home the following point: In a usage-based model which strives for cognitive plausibility, the semi-specific level is an important level one cannot do without. At the same time, the postulation of an abstract overarching schema (i.e., a mothernode) like $\left[\mathrm{CN}_{\mathrm{sg}}{ }^{\mathrm{i}} \mathrm{P} \mathrm{CN}{ }_{\mathrm{sg}}{ }^{\mathrm{i}}\right]_{\mathrm{Cx}}$ or even $[\mathrm{N} \mathrm{P} \mathrm{N}]_{\mathrm{Cx}}$ high up in the network is possible but not really necessary. It is unrealistic that speakers entrench such a general schema in a bottom-up acquisition process for this constructional family. It will be concluded that the discussed NPNs are a type of constructional family characterized by many sister ties and by the absence of mother nodes from which information can be inherited.

The paper will be structured as follows: Section 2 will briefly discuss some characteristic features of the NPN construction and present some of the proposals made so far about the formal and functional status of these binominals. Section 3 will present the results of the empirical analysis. Section 4 will then discuss the different templates and provide a preliminary sketch of the constructional network of symmetric NPN constructions. Section 5 concludes the paper with an outlook on necessary future research.

\section{Symmetric NPNs}

NPN constructions show some interesting non-canonical, syntactic behavior and the observable form-meaning mismatch has inspired a handful of publications. This section briefly discusses some of the characteristic features of NPNs (2.1) and summarizes some of the ideas presented in previous theoretical accounts (2.2). For a more detailed account of distinct features, usage and theoretical modelling in other frameworks see Sommerer (accepted). 


\subsection{Characteristic features}

NPN constructions show some interesting characteristic features. The vast majority of cases consists of a binominal NP with two identical nouns conjoined by a preposition (see examples [1]-[4]). One syntactic restriction is that the construction does not allow any determiners. In the vast majority of cases, the nouns are singular (not mass or plural) and are not pre- nor postmodified. According to Jackendoff, modification and complementation are only possible with after, by and upon and only the second or both nouns can be modified, never the first (2008:9). If you have a modifier or a complement it is interpreted across the board, like in (8) where every day is a hellish day (Haïk 2013: Section 9).

(8) He deflected my question about how he survived day after hellish day in the prison camps (2011, NEWS, Houston)

(9) They've had record-breaking summer after record-breaking summer. (2003, SPOK, CNN_LiveSun)

Complementation is said to only be possible in NPNs which function as arguments (subject and objects) not adjuncts (Jackendoff 2008: 22).

(10) sitting through hour upon hour of numbing discussion about virtually every program in the budget (1993, NEWS, WashPost)

NPNs primarily function as optional adjuncts (examples [1]-[3]) but they can also be found in argument function (subject position (example [4]) and object position (examples [8]-[10]). Additionally, they can be modifiers of a head (example [11]) or Subject Complements (example [12]):

(11) variety of factors that go into causing temperatures to go up and down on a decade to decade basis (COCA, 1991, SPOK, CNN-Crossfire)

(12) paid the rent for another month a couple of days ago. The deal is month by month.

(COCA, 2015, FIC, QuadrantMagazine)

Interestingly, there is a semantic-syntactic mismatch: two entities (nouns) which are combined and semantically create a plural group reading combine with a singular verb (example [13]).

(13) when I hear the stories of person after person who creates his or her own job, regardless of their status in America. (2005, SPOK, CNN_Event) 
In other words, when used as arguments, the NPNs show singular agreement and pick singular pronouns although semantically it could be argued that by conjoining the nouns an unbounded non-singular group reading is created.

In terms of lexical biases this constructional family shows some interesting preferences. As has already been mentioned, NPN constructions are rather constrained with regard to which nouns can be used. In the literature, it has been stated that neither mass nor plural nouns can be conjoined ( ${ }^{\star}$ water after water, ${ }^{*}$ dust for dust, ${ }^{*}$ shoulders to shoulders) (Jackendoff 2008: 9; Quirk et al. 1985: 280). Still, exceptions exist. ${ }^{7}$

One primarily finds temporal units, nouns of measurement or body-parts filling the noun slot (e.g., inch by inch, mile after mile, eye to eye, arm in arm) but not every member of these semantic classes is used ( ${ }^{\star}$ finger in finger). Depending on the semantics of the noun and the semantics of the preposition several different meanings can be expressed. For example, NPNs with the preposition after mostly express some kind of temporal or spatial succession or the stacking of two entities (year after year, mile after mile, brick after brick). NPNs with the preposition to and body-part nouns express some kind of close contact, juxtaposition or opposition (shoulder to shoulder, face to face) (see section 4.1 for a detailed semantic analysis).

Finally, it should be mentioned that for many NPNs a hyphenated version exists in orthography.

(14) When the iPhone $6 \mathrm{~S}$ becomes too slow for your day-to-day use in, say, two years' time, you could upgrade (2017, MAG, BusinessInsider)

(15) So I'd followed the blueprint step-by-step, but now I needed a new set of plans. (2017, FIC, Bk:HisLastName)

The hyphenated examples mostly function as pre-head modifiers. In any corpus study it is necessary to analyse hyphenated as well as non-hyphenated examples.

\subsection{Previous theoretical accounts}

NPNs are briefly mentioned in the Comprehensive Grammars of English. In Quirk et al., NPNs are discussed as "parallel structures" in a section on phrases which omit the article. They are categorized as idioms with “'frozen' article use" (1985: 280). Quirk et al. relate NPNs to expressions like father to son, husband and wife or from beginning to end "where one noun is balanced against another of contrasting meaning" (1985: 280). For Payne and Huddleston, NPNs are "fixed

7 [W] had 20-knot winds on the nose for hours after hours and days after days. (COCA: 2007 MAG MotorBoating) 
frames" (2002: 409) which they discuss in a section on restricted, non-referential bare noun NPs which lack a determiner. In another chapter, they get analyzed as exceptional prepositional phrases (Payne and Huddleston 2002: 632). This twofold analysis hints at the difficulty to decide whether NPNs are PPs or NPs. At the same time, it is debatable what should be considered the construction's head.

Additionally a handful of research papers exists which tackle NPNs in detail. Most of the earlier papers are generative or look at the construction from a philosophical/formal semantics perspective. For example, Beck and Von Stechow take a formal semantics approach and consider NPNs to be "pluractional adverbials" with semantics that they call "pseudoreciprocal" (2006: 43). Heykook and Zamparelli (2003) classify the constructions as "coordinated bare singulars" (CBNs). Matsuyama $(2004,2006)$ argues that NPNs are a subtype of WQNPs (weakly quantified NPs, which are NPs with weak determiners such as many or some). Although NPNs like [N after N] have no overt element of quantification, they are still similar to WQNPs in the sense that they are ambiguous by allowing an existential or presuppositional reading. Also, they are similar to other bare plurals by giving rise to an unbounded interpretation (Matsuyama 2006: 449-451). ${ }^{8}$ Among other things, such analyses account for the missing determiner.

Haïk (2013) treats NPN constructions as symmetric lexical items ${ }^{9}$ postulating two subtypes, namely (a) lexical small clauses like face to face where the proposition is the head and (b) coordinating nominal compounds (e.g., student after student) where the noun is the head. In their typological comparative paper, König and Moyse-Faurie (2009) zoom in on only those NPN constructions which help to encode spatial and metaphorical reciprocity/opposition (face to face) ${ }^{10}$

A completely different approach is put forward by Travis $(2001,2003)$. Travis identifies the process of syntactic reduplication; the material before the preposition is a reduplication of the material in the complement of the preposition. The reduplication has to proceed from right to left and is a formal means to express the semantics of plurality. ${ }^{11}$

From a Construction Grammar point of view, Jackendoff's $(2008,2013)$ work is most important (also see Jackendoff and Audring 2019). He bases his analysis on his Simpler Syntax Hypothesis (Culicover and Jackendoff 2005) but also relates his work to Fillmore et al. (1988) and Goldberg (2006). Jackendoff, following Culicover

\footnotetext{
8 Note that Matsuyama focuses exclusively on the $\mathrm{N}$ after $\mathrm{N}$ construction.

9 In the sense of being formed by morphological/ word formation rules.

10 Also see Pskit $(2015,2017)$ for a comparative approach of Polish and English.

11 Zwarts (2013) relates the NPN type to so-called FNTN constructions [from N to N] and Kim and Sells (2015) compare the structure to (E)BNPs (i.e., evaluative binominals) like $a$ hell of a ride or $a$ jewel of a city.
} 
(1999), calls NPNs "syntactic nut[s]" with an unclear categorical status. He also stresses their "entrenched noncanonical structure" (2008: 8) which violates the binary X-bar schema which is postulated in generative models. Jackendoff and Audring argue that the NPN family consists of a list of idioms plus five productive sub constructions (2019: 238). It is argued that the five subtypes have an ancestor [N P N] from which they inherit their idiomatic (non-productive) form, but the used prepositional subtypes ([N by $\mathrm{N}],[\mathrm{N}$ for $\mathrm{N}]$, [N after $\mathrm{N}]$, [N upon $\mathrm{N}]$, [N to $\mathrm{N}]$ ) create their own semantics (Jackendoff and Audring 2019: 57). It remains to be seen if Jackendoff's claim is corroborated by the empirical data analysis. Note that we - in contrast to Jackendoff and some other construction grammarians - will argue against the postulation of highly abstract formal templates for this constructional family (see section 4.2).

Almost all of the listed papers emphasize that it is difficult to assign lexical or grammatical status to the construction. They acknowledge the difficulty to detect a general meaning which all types share. Also, the authors highlight that the constructional types differ in their compositionality, productivity and general behavior. For example, it is said that [N after $\mathrm{N}]$ behaves differently and is more flexible than the other types. None of the mentioned papers, however, bases its line of argumentation on a large scale quantitative empirical analysis. This brings us to the empirical set up of this study and its limitations.

\section{Empirical analysis}

To analyze the constructional family at hand, this paper uses data from the online version of the Corpus of Contemporary American English (Davies 2008-). Examples were extracted before March 2020. ${ }^{12}$ The empirical investigation is limited in that it only investigates NPNs with singular temporal nouns. Plural nouns and nouns with different semantics (body parts, measure nouns, ...) were not investigated in a quantitative manner. Although this limitation has to be overcome in the future, the empirical analysis was limited to temporal nouns for multiple reasons:

First, temporal NPNs are the most frequent ones in terms of token frequency compared to the other types, which is why we considered them a representative start. However, we are fully aware of the fact that the other subtypes may behave differently (especially in terms of their semantics and syntactic roles). Second, the

12 Since March 2020, the corpus has almost doubled in size and new genres have been added. However, the analysis in this paper is based on data which were extracted in June 2019. This means that the analysis is limited to the 'original' genres ACAD, MAG, FIC, SPOK and NEWS and examples only go up to the year 2017. https://www.english-corpora.org/coca/ 
online version of the COCA does not allow users to run a search query in which any singular common noun $\left({ }^{\star} n n 1^{\star}\right)$ is immediately followed by a preposition $\left(\mathrm{i}^{\star}\right)$ which is again followed by another singular common noun (_*nn $\left.1^{\star}\right)$. Such a query apparently yields too many results (more than 40,000,000 examples) and the interface does not provide any concordance lists for such a query. This limitation impedes a comprehensive search for all types of NPN constructions. Admittedly, it is theoretically possible to overcome this setback by specifying the preposition in every query and looking for each preposition individually but this would have been extremely time consuming and results also often exceed the allowed search options. Third, the paper zooms in on temporal nouns in order to enable a thorough qualitative investigation. As every found example was analyzed qualitatively one by one and tagged for various characteristic features, looking at other types was postponed to future research. Still, the nature and constructional status of constructions like inch by inch or face to face will be discussed from a theoretical point of view in section 4 of the paper. In general, we argue that not looking at the other types quantitatively does not devaluate our overall theoretical conclusions regarding the assumed architecture of the construction.

\subsection{Data}

Following the UCREL CLAWS7 Tagset, the main search query was ${ }_{-}^{\star} n n t 1^{\star}$ i $^{\star}$ ${ }_{-}^{\star}$ nnt $1^{\star}$. By running this query, the search could be limited to temporal nouns used with all prepositions. We ended up with a long list of collocating phrases, which included many cases with non-identical nouns, like time of night, time of year, or day after Christmas. After this noise was excluded, more than 12.000 examples remained where the nouns were identical. All those examples were sifted through one by one, to exclude examples which were not NPNs in the first place. For instance, (16) and (17) had to be excluded as the two nouns are not part of the same noun phrase:

(16) He says he didn't like reading before this summer in summer school (1995 SPOKEN NPR_ATC)

(17) This is the time to work out your own rhythms for balancing couple time versus time for yourself and time with friends and family. (1998 MAG Redbook $)^{13}$

13 Moreover, all hits were excluded in which the string was part of another larger construction altogether, for instance [X in X out] day in day out. All strings with a naming expression referring to a product or to a specific referent were excluded as well (the 'Day to Day TV show', or the 'Time after Time' Song by Cindy Lauper). 
9,571 examples remained. As a next step, the hyphenated counterparts of all the constructional types were extracted. 5,427 hyphenated examples could be found. Note that an example like day to day and its hyphenated alternative day-to-day are counted as one type in this study. All the examples were tagged for the following characteristic features: type of noun, type of preposition, syntactic function, and interesting clustering patterns. Additional queries were run to investigate modification and complementation. The next section reports on some of the findings.

\subsection{Analysis}

\subsubsection{Descriptive statistics: frequency and productivity}

Overall, 14,998 examples of NPNs were identified. 26 different nouns and 11 different prepositions are being used in the construction; we find 86 different constructional types among them 21 hapaxes (e.g., season upon season, dusk to dusk, minute per minute). ${ }^{14}$

Table 1: Overall frequency of $\left[\mathrm{CN}_{\mathrm{sg}, \text { time }} \mathrm{P}^{\mathrm{i}} \mathrm{CN}_{\mathrm{sg}, \mathrm{time}}{ }^{\mathrm{i}}\right]_{\mathrm{Cx}}$.

\begin{tabular}{ll}
\hline SEARCH STRING: _. ${ }^{*} n 1^{*}{ }^{*}{ }^{*}{ }^{*}{ }^{*}$ nnt1*$^{*}$ & COCA (05.06.2019) \\
\hline $\begin{array}{l}\text { Occurrence (incl. hyphenated and } \\
\text { non-hyphenated examples) }\end{array}$ & 14,998 hits \\
Different constructional types & 86 (21 hapaxes) \\
Number of different nouns & 26 \\
Number of different prepositions & 11 \\
& (after, to, by, over, upon, for, on, through, onto, \\
& following, within) \\
\hline
\end{tabular}

The ten most frequent constructional types are listed in Table 2. Figure 1 reveals which nouns are used most frequently in the construction.

Day, year and night are the temporal nouns recruited most often in the noun slot in terms of token frequency. This comes as no surprise, as year, day and night (in that order) are also the most frequent temporal nouns in general. We can assume that speakers simply like to talk more about their days and nights than about their millennium.

Table 3 ranks the used prepositions based on their frequency. To is the most frequently used preposition (used in about one half of the cases), followed by after

14 The complete list can be found in Table 1 in the Supplementary Material. 
Table 2: Top 10 of temporal NPN types in the COCA (raw frequency).

\begin{tabular}{lrll}
\hline Construction & Frequency & Noun & Prep \\
\hline Day to day/day-to-day & 5,037 & Day & To \\
Year after year/year-after-year & 1,660 & Year & After \\
Day after day/day-after-day & 1,418 & Day & After \\
Year to year/year-to-year & 928 & Year & To \\
Day by day/day-by-day & 900 & Day & By \\
Night after night/night-after-night & 695 & Night & After \\
Time after time/time-after-time & 501 & Time & After \\
Week after week/week-after-week & 402 & Week & After \\
Year over year/year-over-year & 301 & Year & Over \\
\hline
\end{tabular}

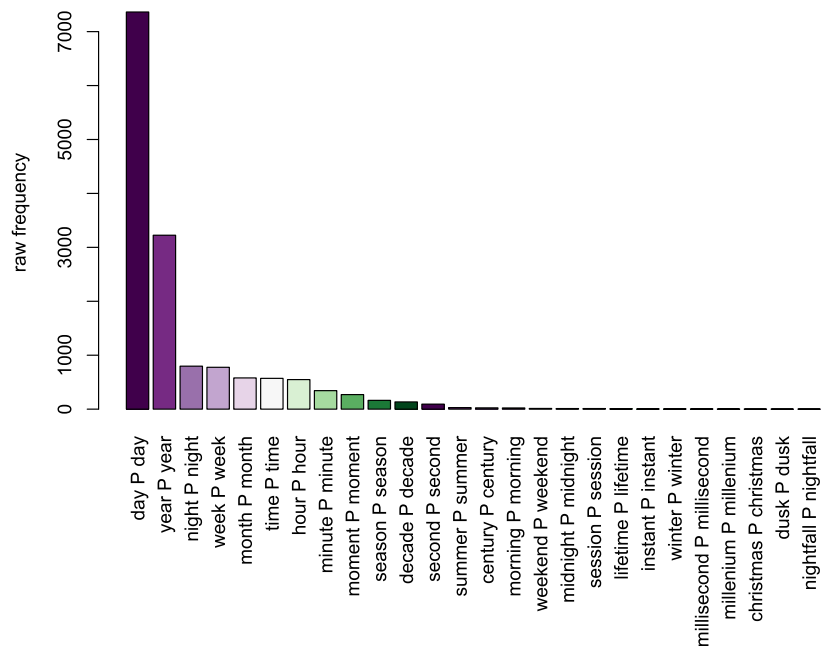

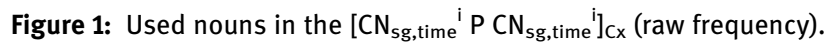

and by. Then, lagging behind with a much lower frequency, we find over, upon, for and the rest.

After is the most productive preposition in the sense that it combines with 22 different nouns followed by to (20), by (17), upon (8), for, on, over (all 5), through, onto, following, and within (all 1). These findings extend Jackendoff's list of prepositions which states that after, by, upon, to and for are used in the construction.

Figure 2 shows prepositions (purple) and nouns (green) together in a productivity graph in which two nodes are linked if they surface in the $\left[\mathrm{CN}_{\mathrm{sg} \text {,time }}{ }^{\mathrm{i}} \mathrm{P} \mathrm{C} \mathrm{CN}_{\mathrm{sg} \text {,time }}{ }^{\mathrm{i}}\right]_{\mathrm{Cx}}$ template at least once, while the size of a node corresponds to its frequency in the analyzed data set. The graph shows a large number of nodes and edges. 
Table 3: Use of prepositions in temporal NPNs.

\begin{tabular}{lrrr}
\hline Preposition & Frequency & $\%$ & Productivity \\
\hline To & 7,126 & 47.51 & 20 \\
After & 5,442 & 36.28 & 22 \\
By & 2006 & 13.38 & 17 \\
Over & 309 & 2.06 & 5 \\
Upon & 55 & 0.37 & 8 \\
On & 41 & 0.27 & 5 \\
For & 15 & 0.10 & 5 \\
Following & 1 & 0.01 & 1 \\
Onto & 1 & 0.01 & 1 \\
Through & 1 & 0.01 & 1 \\
Within & 1 & 0.01 & 1 \\
\hline
\end{tabular}

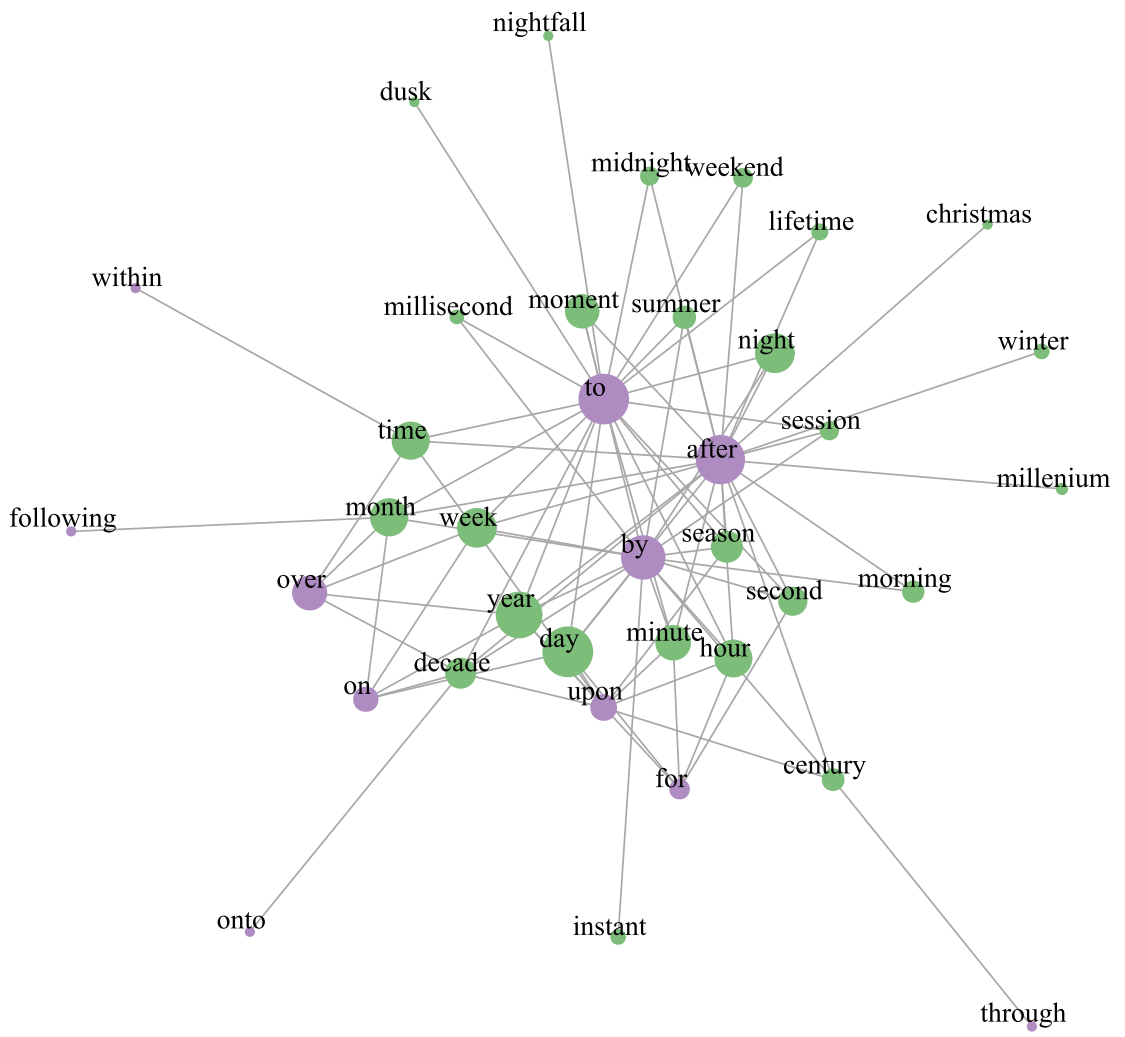

Figure 2: Productivity graph of nouns and prepositions in $\left[\mathrm{CN}_{\mathrm{sg} \text {,time }}{ }^{i} \mathrm{P} \mathrm{CN}_{\mathrm{sg} \text {,time }}{ }^{i}\right]_{\mathrm{Cx}}$ constructions. Two nodes (purple: prepositions; green: nouns) are linked if they surface together at least once in $\left.\left[\mathrm{CN}_{\mathrm{sg}} \text {,time }{ }^{i} \mathrm{P} \mathrm{CN}_{\mathrm{sg} \text {,time }}\right]_{\mathrm{Cx}}\right]_{\mathrm{c}}$. Node sizes scale with log-frequency of the respective item in the data set of about 15,000 tokens. 
After, to and by are both central in the graph (being linked to many nouns) as well as relatively frequent. Additionally, some prepositions and nouns, such as day and by, productively pair up in the sense that they are linked and have a high frequency.

\subsubsection{Collostructional analysis}

In order to shed more light on the lexical preferences (i.e., repulsion/attraction strength) in the construction, we conducted a simple collexeme analysis (e.g., Stefanowitsch 2006, 2013; Stefanowitsch and Gries 2003) with some minor adjustments to overcome statistical shortcomings (see Schmid and Küchenhoff 2013). Although collostructional analysis à la Stefanowitsch and Gries has been criticized for various reasons (e.g., Divjak 2008; Schmid 2010; Schmid and Küchenhoff 2013), it is a useful method to calculate the association strength between a construction and the lexical items filling a slot in it.

For every temporal noun, we measured the strength of association with the $\left[\mathrm{CN}_{\text {sg,time }}{ }^{\mathrm{i}} \mathrm{P} \mathrm{CN}_{\mathrm{sg} \text {,time }}{ }^{\mathrm{i}}\right]_{\mathrm{Cx}}$ template. We computed a 2-by-2 contingency table containing four different scores for frequencies of occurrence; namely the frequency of the target lexeme in the target construction (A), the frequency of the target lexeme in the corpus in general (B), the frequency of the construction filled with other lexemes than the target lexeme $(C)$ and the frequency of all other constructions with lexemes other than the target (D). From these frequencies, one can derive the expected frequency of occurrence and whether the observed frequency of the noun in the construction deviates significantly. From the contingency table, we derived log odds ratio together with 95\% confidence interval for every noun (Schmid and Küchenhoff 2013). If the log odds ratio is significantly positive, the noun is said to be attracted to the construction. If it is significantly negative, it is considered to be repelled. ${ }^{15}$

The results are visualized in Figure 3 (numerical results can be found in Table A2 in the Supplementary Materials). It can be seen that six nouns are significantly attracted by the construction (purple bars), whereas others are repelled (green bars). In other words, in contrast to their raw frequency distribution, the nouns show a slightly different ranking when it comes to their attraction strength. For example, the nouns millisecond or hour are used relatively more often in the construction than the high frequency nouns night or week. In contrast, other nouns like morning, winter and Christmas are repelled. Compared to their rather frequent overall usage in the corpus, they do not show up as often as expected in the $\left[\mathrm{CN}_{\mathrm{sg} \text {,time }}{ }^{\mathrm{i}} \mathrm{P} \mathrm{CN}_{\mathrm{sg}, \text { time }}{ }^{\mathrm{i}}\right]_{\mathrm{Cx}}$ template.

We can also assess collostructional strength for each preposition separately. This allows us to inspect, for example, which nouns are attracted most by the

15 All computations were done in R (R Development Core Team 2018). 
collostructional strength $\log (\mathrm{OR})$

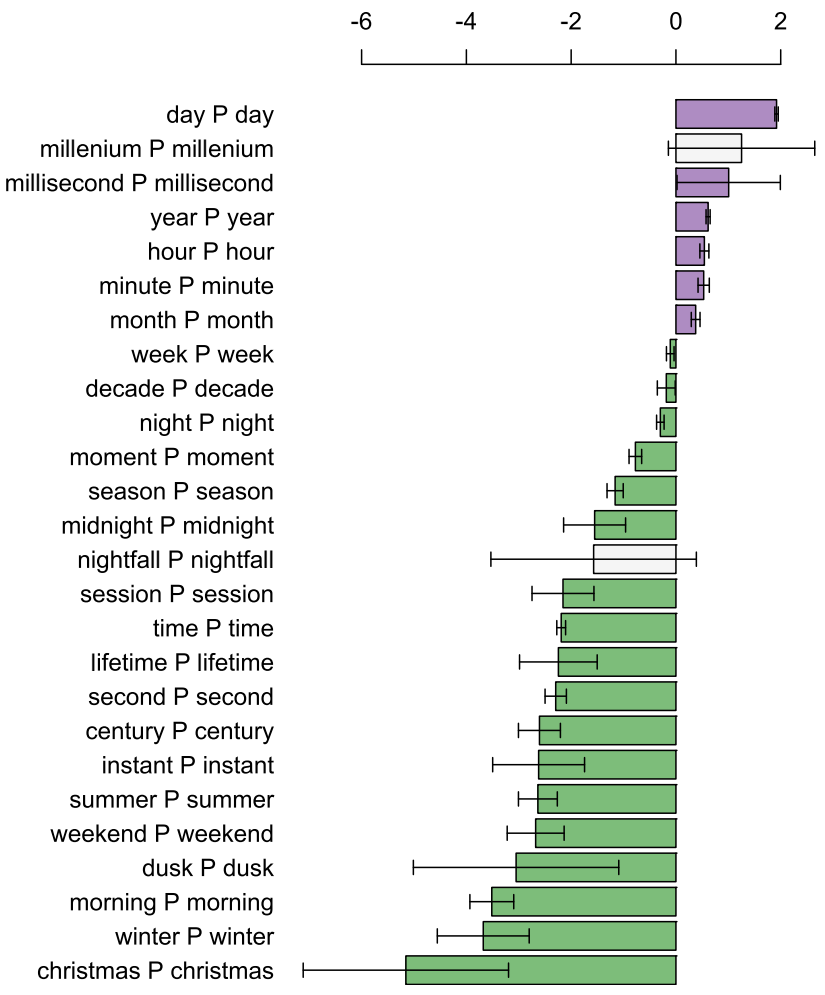

Figure 3: Collostructional strengths of all $\left[\mathrm{CN}_{\mathrm{sg}, \text { time }}{ }^{i} \mathrm{P} \mathrm{CN}_{\mathrm{sg}, \mathrm{time}}{ }^{i}\right]_{\mathrm{Cx}}$ constructions. Strength is measured by $\log (\mathrm{OR})$ (horizontal axis). Error bars denote $95 \%$ confidence intervals. Purple denotes attracting constructions ('attractor'; $\log (\mathrm{OR})$ significantly positive); green denotes repelling constructions ('repellor'; $\log (\mathrm{OR})$ significantly negative); light gray denotes constructions which are neither repellors nor attractors.

$\left[\mathrm{CN}_{\mathrm{sg} \text {,time }}{ }^{\mathrm{i}} \text { after } \mathrm{CN}_{\mathrm{sg} \text {,time }}{ }^{\mathrm{i}}\right]_{\mathrm{Cx}}$ template. We performed a collostructional analysis as above for each preposition in our dataset (by just filtering all corresponding items and then computing $\log (\mathrm{OR})$ for each noun as described before). Based on the collostructional analysis we determined the significantly attracting nouns for each preposition.

All nouns and prepositions were again arranged in a graph in such a way that a noun and a preposition are linked if the preposition is significantly attracted by that noun as determined through the collostructional analysis. The resulting graph is displayed in Figure 4 (nouns are green; prepositions are purple; arrows denote attraction). Such an analysis is both more revealing and statistically robust than the production graph in Figure 2. Evidently, not all prepositions are attracted by the same set of nouns in the construction. For example, after and by only share three 
attracting nouns (hour, month, day), and each of the two features additional attractors as well (decade, night, week, millennium for after; minute, millisecond for by). Conversely, not all nouns (apart from month and day) point to the same prepositions. In particular, year and day (both of which represent attractors for the more abstract construction as seen in Figure 4) have almost disjoint sets of attractees.

How are these results relevant for our constructional analysis? In general, a usage-based framework assumes that "the frequencies of repeated processing events translate into different strengths of associations in the network representing linguistic knowledge" (Schmid and Küchenhoff 2013). The postulation of constructions (as separate nodes in the cognitive network) can be based on their degree of entrenchment and their attraction strength. Although there is not always a direct link between corpus data and degree of entrenchment, it is usually assumed that a construction is more strongly cognitively entrenched, if it is frequently encountered (Blumenthal-Dramé 2012; Bybee 2010; Diessel and Hilpert 2016; Hilpert and Diessel 2016; Schmid 2010). If a string is cognitively strongly entrenched, this warrants its constructional status as a separate node in the construction.

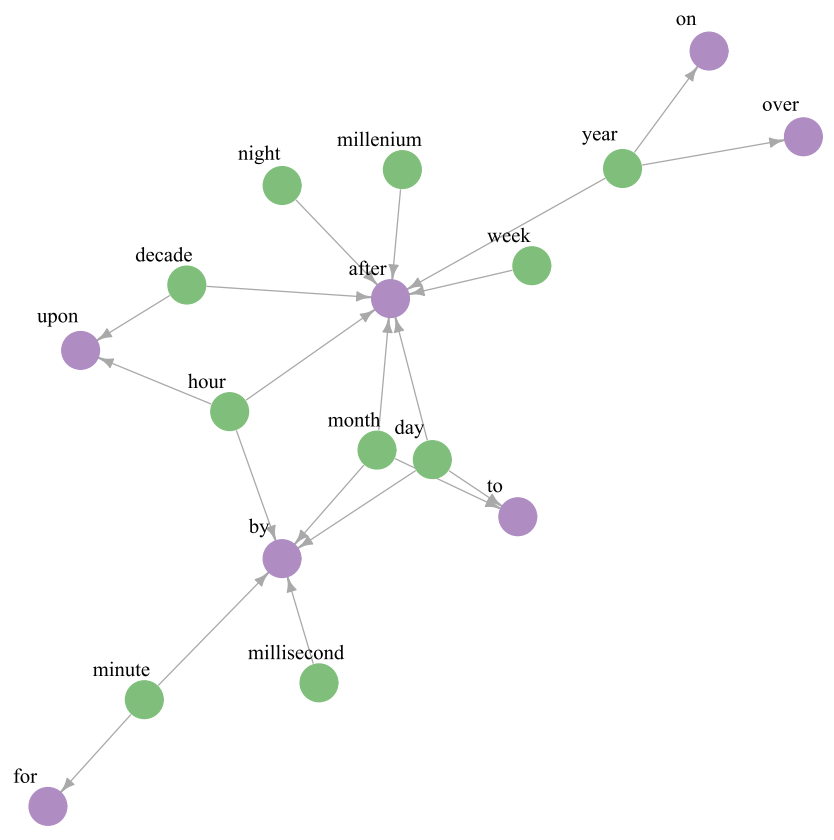

Figure 4: Attractor graph for nouns (green) and prepositions (purple) in $\left[\mathrm{CN}_{\mathrm{sg}, \text { time }}{ }^{i} \mathrm{P} \mathrm{CN}_{\mathrm{sg}, \mathrm{time}}{ }^{i}\right]_{\mathrm{Cx}}$ templates. Two nodes are linked if one node is significantly attracted by the other node (gray arrow pointing to the attractee). Attractors were determined by computing a collostructional analysis for each preposition separately. 
Thus, it is possible to argue that constructions like year after year or day by day (see Table 2) deserve to be represented as individual separate nodes in the network due to their high frequency. Although they are rather compositional and transparent in their meaning, they are extremely frequent in contrast to the other temporal NPN constructions. At the same time, collostructional analysis reveals that a noun like minute is also recruited relatively often into the construction. So even if minute has a rather low token frequency at first sight, it can be argued that speakers hear minute relatively often in the NPN pattern in contrast to how often they hear it in other 'normal' NPs. Moreover, as can be seen from Figure 4, minute has its own dedicated attractee for, which is not shared with any other noun. This may lead to the cognitive strengthening of this low frequency pattern as well.

\subsubsection{Modification and complementation}

As has been mentioned in the introduction, modification is another aspect worthy of investigation. ${ }^{16}$ In the research literature on the topic, it is stated that modification and complementation patterns in these constructions are quite rare.

The pup would be taken to good rabbit habitat time after endless time. (1992, MAG, Outdoorlife)

Jackendoff points out that only those NPs which function as arguments can take complements (examples [19] and [20]).

people who are watching us are not going to see minute after minute of planes hitting towers and towers collapsing (2002, SPOK, CNN_Reliable)

I remember Mother playing hour after hour of dominoes in the library $(1995 \text {, FIC, ParisRev })^{17}$

Additionally, Jackendoff claims that modification is only possible with after, by and upon. No study however, has so far investigated the frequency and nature of these modified patterns. Our analysis reveals that a handful of examples with the

16 To find instances of modification and complementation two additional queries were run: [ _ $\left.{ }^{\star} n n t 1^{\star}{ }_{-} i^{\star}{ }_{-} j^{\star}{ }_{-}{ }^{\star} n n t 1^{\star}\right]$ and $\left[{ }_{-}{ }^{\star} n n t 1^{\star}{ }_{-} i^{\star}{ }_{-}{ }^{\star} n n t 1^{\star}\right.$ of $]$ and any noise was excluded. Note that the hyphenated examples are not investigated here as they mostly function as prehead modifiers which in that position neither take modifiers nor complements.

17 By "modification”, we mean adjectival pre-head modifiers. By "complementation", we mean all post-head elements introduced by of. In other words, we do not distinguish between the various post-head elements. For example, it is debatable whether of dominoes in example (20) should be classified as a complement (semantically obligatory) or as a post-head modifier (semantically optional). In this paper, no such distinction is being made and all cases of post-head marking are analyzed as cases of complementation. 
preposition to exist (21) and that NPNs with complementation can also function as adjuncts as well (22).

(21) And not get swept up in, you know, the day-to-day, minute to minute of politics in the Twitter sphere (2017, SPOK, CNN: Axe Files)

(22) Day after day of the crisis, we saw men and women working side by side (1991, SPOK, ABC_Nightline)

The results confirm that, overall, modified and complemented examples are extremely rare. As Table 4 reveals, only 62 examples have a modified second noun. In contrast to thousands of hits without a modifier, this corresponds to less than $1 \%$ of temporal NPNs that were found. 12 different noun types take a modifier. Modified examples can be found with four different prepositions, although in the vast majority of cases (54) the preposition is after. In only three examples we find modification of the first and the second noun (see examples in Table 4). Jackendoff's claim that only the second or both nouns can be modified, never the first turns out to be correct. In none of the examples, only the first noun gets modified.

Post-modification is slightly more frequent with 142 examples. Again, complementation patterns only occur with the prepositions after, by, to and upon and again NPNs with after take complementation most often.

Table 4: Pre-modification/post-modification/complementation of temporal NPNs.

\begin{tabular}{|c|c|}
\hline 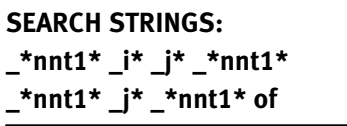 & COCA (05.06.2019) \\
\hline $\begin{array}{l}\text { Occurrence of non-modified } \\
\text { (non-hypenated) }\end{array}$ & 9,570 hits \\
\hline Modification of N2 & $\begin{array}{l}64 \\
13 \text { different nouns } \\
4 \text { different prepositions } \\
\text { after (56) by (6) to (1) upon (1) }\end{array}$ \\
\hline Modification of N1 and N2 & $\begin{array}{l}3 \text { (disastrous season after disastrous season; split second after } \\
\text { split second; record-breaking summer after record-breaking } \\
\text { summer) }\end{array}$ \\
\hline Complementation & $\begin{array}{l}142 \\
15 \text { different nouns } \\
4 \text { different prepositions } \\
\text { after (122) by (1) to (1) upon (17) }\end{array}$ \\
\hline Both & 1 (day after desperate day of unbroken siege) \\
\hline
\end{tabular}


In the corpus, there is only one example in which modification and complementation occur together: day after desperate day of unbroken siege. The extremely low frequency of modification and complementation in this type of binominal constructions highlights their status as constructions with a rather high degree of fixedness. What this means for constructional modeling will be discussed below.

\section{Constructional sketch}

Before presenting a constructional sketch of the NPN family, we would like to briefly recap some of the most important tenets of UCCxG. It is assumed that a language consists of constructions; i.e., conventionalized, cognitively entrenched form-meaning pairings in the sense of de Saussure (Diessel 2011: 830; Goldberg 2006: 3). Single words, but also more complex phrasal constructions (e.g., binominal noun phrases), are conceptualized as symbolic signs, which link a formal side to a particular meaning/function via a symbolic correspondence link (Croft and Cruse 2004: 258). There is no conceptual divide between the lexicon (lexical entries) and grammar (syntactic rules). Rather, the constructions of a language only differ in their idiomaticity, schematicity and their (semantic and syntactic) complexity, and can be "placed on a lexicon-syntax continuum" (Hoffmann and Trousdale 2013: 2). Rules (in the traditional generative sense) have been replaced by schemas (i.e. grammatical templates which have evolved over concrete tokens). Grammatical code is meaningful: abstract, lexically underspecified grammatical templates exist which themselves carry 'procedural' meaning that is often independent of the meaning of individual semantic elements which are used to fill the templates. Note that UCCxG does not assume the existence of 'meaningless' constructions.

All the constructions of a language form the 'constructicon': "a structured inventory, which can be represented by multiple inheritance networks" (Croft and Cruse 2004: 262-265). Linguistic knowledge is presented in twodimensional networks where lower level constructions are said to inherit features from higher level constructions through vertical links (parent-daughter relations) and in which related constructions on the same level of complexity can also be linked horizontally (sister relations). This creates so-called 'constructional families' of closely linked constructions that are semantically and formally related. Crucially, Inheritance is 'top down' but acquisition of a speaker's constructicon is mainly 'bottom up' in the sense that a speaker 
abstracts over fully specified concrete strings, which in ontogeny are mostly acquired first (Diessel 2019; Tomasello 2003). ${ }^{18}$

Finally, UCCxG is a usage based, non-nativist, non-reductionist, inventorybased approach in the sense that all linguistic generalizations including syntactic abstract templates are derived from the user's experience with language (actual usage events). It is assumed that statistical performance factors influence the structure of the code; high type and token frequency lead to stronger cognitive entrenchment. Any postulated linguistic categories are emergent and language specific. Also, the model allows for redundancy in mental storage, as memory is cheap but computation is costly (for more details about the approach, see, for example, Blumenthal-Dramé 2012; Croft 2001; Croft and Cruse 2004; Diessel 2015, 2019; Divjak 2019; Goldberg 2019; Hilpert 2014; Hoffmann and Trousdale 2013; Tomasello 2003).

Keeping these general assumptions in mind, let us turn to the NPN family. Coming back to the questions raised in the introduction, the following issues will be discussed in the following subsections: (a) when should a separate node in the network be postulated and (b) is it always feasible, cognitively realistic and necessary to abstract to a very high schematic level? Note that our line of argumentation rests on the idea that empirical corpus evidence, although indirect, can tell us something about mental storage and cognitive processing.

\subsection{How many family members? Postulation of individual NPN constructions}

\subsubsection{The semi-specified midlevel and why it exists}

The corpus analysis presented in section 3 shows that speakers often encounter constructs like day after day, night after night or year after year. Subscribing to a usage-based model of acquisition we assume that the language learners at one point detect formal and semantic similarities between the constructions and abstract a more general schema, namely $\left[\mathrm{CN}_{\mathrm{sg}, \text { time }}{ }^{\mathrm{i}} \text { after } \mathrm{CN}_{\mathrm{sg}, \mathrm{time}}{ }^{\mathrm{i}}\right]_{\mathrm{Cx}}$.

The question is how many of those semi-specified templates we intend to postulate? The empirical analysis has revealed that 11 different prepositions are being used. This could make us postulate the following templates:

18 Note that a speaker's constructicon is constantly changing and new constructions on all levels can emerge at any point. In that sense, it is also possible that even after abstract schemas have constructionalized, more specific templates can be added which preempt the usage of the abstract templates. 


$$
\begin{aligned}
& {\left[\mathrm{CN}_{\mathrm{sg}, \text { time }}{ }^{\mathrm{i}} \text { to } \mathrm{CN}_{\mathrm{sg}, \text { time }}{ }^{\mathrm{i}}\right]_{\mathrm{Cx}}} \\
& {\left[\mathrm{CN}_{\mathrm{sg}, \text { time }}{ }^{\mathrm{i}} \text { after } \mathrm{CN}_{\mathrm{sg} \text {,time }}{ }^{\mathrm{i}}\right]_{\mathrm{Cx}}} \\
& {\left[\mathrm{CN}_{\mathrm{sg} \text {,time }}{ }^{\mathrm{i}} \text { by } \mathrm{CN}_{\mathrm{sg} \text {,time }}{ }^{\mathrm{i}}\right]_{\mathrm{Cx}}} \\
& {\left[\mathrm{CN}_{\mathrm{sg} \text {,time }}{ }^{\mathrm{i}} \text { over } \mathrm{CN}_{\mathrm{sg} \text {,time }}{ }^{\mathrm{i}}\right]_{\mathrm{Cx}}} \\
& {\left[\mathrm{CN}_{\mathrm{sg} \text {,time }}{ }^{\mathrm{i}} \text { upon } \mathrm{CN}_{\mathrm{sg} \text {,time }}{ }^{\mathrm{i}}\right]_{\mathrm{Cx}}} \\
& {\left[\mathrm{CN}_{\mathrm{sg} \text {,time }}{ }^{\mathrm{i}} \text { for } \mathrm{CN}_{\mathrm{sg}, \text { time }}{ }^{\mathrm{i}}\right]_{\mathrm{Cx}}}
\end{aligned}
$$

$$
\begin{aligned}
& {\left[\mathrm{CN}_{\mathrm{sg}, \text { time }}{ }^{\mathrm{i}} \text { on } \mathrm{CN}_{\mathrm{sg}, \mathrm{time}}{ }^{\mathrm{i}}\right]_{\mathrm{Cx}}} \\
& {\left[\mathrm{CN}_{\mathrm{sg}, \text { time }}{ }^{\mathrm{i}} \text { following } \mathrm{CN}_{\mathrm{sg}, \text { time }}{ }^{\mathrm{i}}\right]_{\mathrm{Cx}}} \\
& {\left[\mathrm{CN}_{\mathrm{sg} \text {,time }}{ }^{\mathrm{i}} \text { through } \mathrm{CN}_{\mathrm{sg}, \mathrm{time}}\right]_{\mathrm{Cx}}} \\
& {\left[\mathrm{CN}_{\mathrm{sg}, \text { time }}{ }^{\mathrm{i}} \text { onto } \mathrm{CN}_{\mathrm{sg}, \text { time }}{ }^{\mathrm{i}}\right]_{\mathrm{Cx}}} \\
& {\left[\mathrm{CN}_{\mathrm{sg}, \text { time }}{ }^{\mathrm{i}} \text { within } \mathrm{CN}_{\mathrm{sg}, \mathrm{time}}\right]_{\mathrm{Cx}}}
\end{aligned}
$$

We could position all these semi-specific templates next to each other as sister nodes with horizontal links between them. ${ }^{19}$ However, at the same time, the empirical analysis shows that the first three templates are extremely frequent $(14,574$ examples) and make up more than $97 \%$ of all the examples. Does this mean that only the first three types should be given constructional status? The crucial question is how frequent a construction has to be in order to deserve its own node in the network. For example, only 15 examples of the $\left[\mathrm{CN}_{\text {sg,time }}{ }^{\mathrm{i}} \text { for } \mathrm{CN}_{\text {sg,time }}{ }^{\mathrm{i}}\right]_{\mathrm{Cx}}$ type can be found in the sample. Similarly, we have 55 cases with upon and 41 one with on. Is this frequent enough to get entrenched as a separate node in the constructicon? If one assumes $\left[\mathrm{CN}_{\mathrm{sg} \text {,time }}{ }^{\mathrm{i}} \text { for } \mathrm{CN}_{\mathrm{sg} \text {,time }}{ }^{\mathrm{i}}\right]_{\mathrm{Cx}}\left[\mathrm{CN}_{\mathrm{sg} \text {,time }}{ }^{\mathrm{i}} \text { on } \mathrm{CN}_{\mathrm{sg} \text {,time }}{ }^{\mathrm{i}}\right]_{\mathrm{Cx}}$ or $\left[\mathrm{CN}_{\mathrm{sg} \text {,time }}{ }^{\mathrm{i}} \text { upon } \mathrm{CN}_{\mathrm{sg} \text {,time }}{ }^{\mathrm{i}}\right]_{\mathrm{Cx}}$, they might not be as strongly entrenched as the others. Especially the for template seems unwarranted; still the empirical analysis has shown that minute for minute is a very special combination which stands out. In fact, any template that shows a significant attraction relationship as shown in Figure 3 can be argued to have its own midlevel node in the network. After all, these templates surface more often than what is expected by chance - and crucially irrespective of how frequent they are. Any potential weaker entrenchment can be visualized by dotted lines around the upon-template in Figure 5. Still, a model which allows redundant storage in an inventory-based approach has no problem to postulate 11 or more sister nodes.

There is a second modelling solution if one wanted to reduce the number of nodes. With four prepositions, only one example was found (month following month, century through century, decade onto decade, time within time). Although these examples can and should not necessarily be dismissed as ill-formed structures or typos, we see them as creative one-offs which most people may consider odd. Their extremely low frequency motivates the following line of argumentation:

19 In $\mathrm{CxG}$, sister nodes are defined in various ways and it is still debated which syntagmatic and paradigmatic relations are expressed by horizontal connections (e.g., Cappelle 2006; Perek 2015; Smirnova and Sommerer 2020; Van de Velde 2014; Zehentner 2019). This paper uses horizontal linking between nodes to express paradigmatic relationships between constructions. 


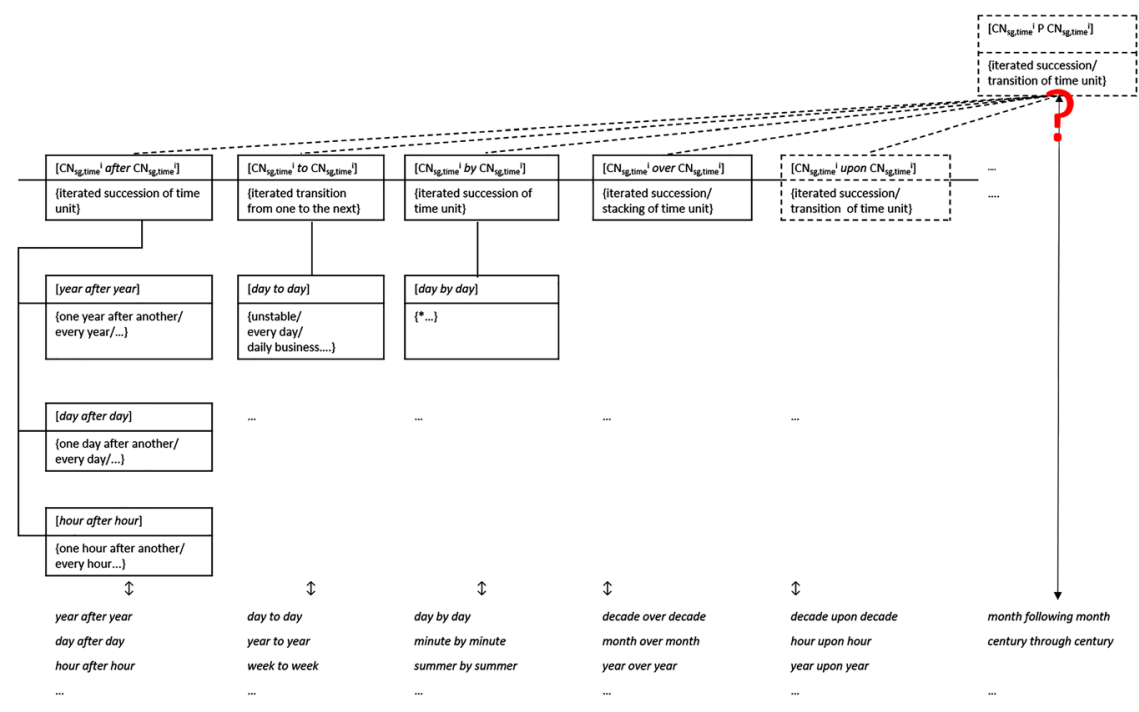

Figure 5: Partial network sketch of temporal NPN constructions.

It could be argued that constructs like this are not separate nodes but are rather licensed by a more abstract template namely $\left[\mathrm{CN}_{\mathrm{sg} \text {,time }}{ }^{\mathrm{i}} \mathrm{P} \mathrm{CN}_{\mathrm{sg}, \text { time }}{ }^{\mathrm{i}}\right]_{\mathrm{Cx}}$. Speakers identify semantic and formal similarities and abstract a more general schema with an unspecified $\mathrm{P}$ slot over the frequent four, which are presumable also diachronically the older ones.

$$
\begin{array}{ll}
\mathrm{F}: & {\left[\mathrm{CN}_{\text {sg,time }}{ }^{\mathrm{i}} \mathrm{P} \mathrm{CN}_{\mathrm{sg}, \text { time }}{ }^{\mathrm{i}}\right]_{\mathrm{Cx}}} \\
\mathrm{M}: & \text { (iterated) succession of time units }
\end{array}
$$

Once such an abstract template is in place on a higher level (see Figure 5), other prepositions can creatively get recruited (a case of host-class extension). ${ }^{20}$ This template is also able to 'generate' the upon, for and on cases. In other words, the template basically takes care of creative extensions and the low frequency

20 Not all speakers of English necessarily have this or any other of the discussed constructions entrenched in their constructicon. Research has shown that individual constructicons will likely differ from each other, especially with regard to the level of abstraction (e.g., Dabrowska 2012). Still, as syntacticians who try to model English grammatical knowledge on an abstract theoretical level, we work with the assumption that the process of emergence or acquisition of a construction works more or less similar for different individuals in a population. 
prepositions. ${ }^{21}$ This modelling solution is quite elegant, as it reduces the number of nodes. Moreover, it is not unlikely that speakers will become aware of the semantic similarity of the various subtemplates and abstract and schematize an overarching more general meaning of \{temporal succession\}.

At the same time, we would like to stress that the postulation of this template is somehow problematic. The 'problem' we see is that the P slot is completely underspecified which means that in principle any preposition could be inserted by the speakers. Still, we observe that many prepositions are not recruited into the construction at all (e.g., under, behind, in). The postulation of this schema thus licenses constructs which basically do not exist and would be considered illformed. This is why one could also argue against the postulation of this mother node in order to explain the lexical restrictions and limitations which clearly exist in this constructional family. That means to simply stop at mid-level and to postulate the existence of many sisters where the preposition is specified. We are in favor of the second solution, even if it is less elegant. Ultimately, however, we are aware that this is a question up for debate, which we have tried to express by the red question mark in Figure 5. One of the crucial questions in Construction Grammar is if it is always feasible, cognitively realistic and necessary to assume the existence of higher, more abstract nodes in the construction. In other words, the question is if (a) speaker(s) - in the case of our NPN templates - abstract to the higher level in the bottom up acquisition process. We will come back to the issue of mother nodes in 4.2; before that, however, we would like to zoom in on the semantics of the semi-specific and the fully specified level.

The postulation of any construction can but should not only be based on frequency, attraction or formal peculiarity. Semantic idiomaticity has always been the strongest argument for the postulation of a construction. In UCCxG, constructions are defined as form-meaning pairings. This begs the question which meaning and discourse-pragmatic function the speakers will assign to the schemas just mentioned and if they are very different from each other. In the case of $\left[\mathrm{CN}_{\mathrm{sg} \text {,time }}{ }^{\mathrm{i}} \text { after } \mathrm{CN}_{\mathrm{sg} \text {,time }}{ }^{\mathrm{i}}\right]_{\mathrm{Cx}}$, the data analysis (also see the examples in the previous sections) suggests that the semantic 'pole' of this construction can be described by succession of time units\}. At the same time, there is a difference between (a) She tries to survive every day and (b) She tries to survive day after day. Every day sounds rather neutral whereas day after day - by iconically reduplicating

21 If an extended empirical sample reveals that the prepositions following, through, within ... are more productive than the COCA data suggests, nothing would stop us from postulating additional, semi-specific nodes. When speakers start to recruit these prepositions more often in the future, the pattern may become truly productive. Then, the constructional network would also be reconfigured by adding new sister nodes like $\left[\mathrm{CN}_{\mathrm{sg} \text {,time }}{ }^{\mathrm{i}} \text { following } \mathrm{CN}_{\mathrm{sg} \text {,time }}{ }^{\mathrm{i}}\right]_{\mathrm{Cx}}$. 
the temporal noun - foregrounds some intensification, highlighting the aspect of repetitiveness and strenuousness. In the vast majority of examples, the NPN string has a negative touch. The speaker stresses that an action is being performed and repeated in a loop-like manner. Therefore, we argue that the NPN construction expresses some interpersonal stance. As a reaction, we postulate the following form-meaning pairing:

(23) F:

Syn: $\quad\left[\mathrm{CN}_{\mathrm{sg}, \text { time }}{ }^{\mathrm{i}} \text { after } \mathrm{CN}_{\mathrm{sg}, \text { time }}{ }^{\mathrm{i}}\right]_{\mathrm{Cx}}$

M:

Sem: $\quad$ iterated succession of time units/many instances in succession\}

Dis-Prag: $\quad$ intensification (negative stance)

The $\left[\mathrm{CN}_{\mathrm{sg} \text {,time }}{ }^{\mathrm{i}} \text { to } \mathrm{CN}_{\mathrm{sg} \text {,time }}{ }^{\mathrm{i}}\right]_{\mathrm{Cx}}$ is slightly different. In a sentence like She tries to survive day to day, it is possible to assign a similar reading like the one postulated for after, namely \{every day/many days in succession\}. Often, however, the NPN expresses some kind of temporal transition, in the sense of ffrom one month to the next month\}. ${ }^{22}$ Again, this template often expresses some negative stance:

(24) F:

Syn: $\quad\left[\mathrm{CN}_{\mathrm{sg}, \text { time }}{ }^{\mathrm{i}} \text { to } \mathrm{CN}_{\mathrm{sg}, \text { time }}{ }^{\mathrm{i}}\right]_{\mathrm{Cx}}$

M:

Sem: $\quad$ (iterated) temporal transition from one time unit to another time unit\}

Dis-Prag: $\quad$ intensification (negative stance) $\}$

The preposition by in $\left[\mathrm{CN}_{\mathrm{sg}, \mathrm{time}}{ }^{\mathrm{i}} \text { by } \mathrm{CN}_{\mathrm{sg}, \text { time }}{ }^{\mathrm{i}}\right]_{\mathrm{Cx}}$, mostly expresses \{succession but somehow foregrounds the procedure of measuring/scrutiny. Using this template does not express annoyance or any negative stance compared to the other templates (Computers track each operation second by second/ hour by hour/day by day).

(25) F:

Syn: $\quad\left[\mathrm{CN}_{\mathrm{sg}, \mathrm{time}}{ }^{\mathrm{i}} \text { by } \mathrm{CN}_{\mathrm{sg}, \text { time }}{ }^{\mathrm{i}}\right]_{\mathrm{Cx}}$

M:

Sem: $\quad$ (iterated) succession of time unit $\}$

Dis-prag: -

22 The final meaning is also influenced by verb choice; compare (a) The numbers changed month to month and (b) They published the numbers month to month. 
It would go beyond the scope of this paper to discuss the meanings of all templates in detail; the three examples suffice to show that the prepositions can often be used synonymously but some semantic interpretations are restricted to a particular preposition. This is why one simply cannot 'delete' the semi-specific level to increase the model's efficiency or to avoid redundancy. In other words, the network cannot 'work' with only a $\left[\mathrm{CN}_{\mathrm{sg} \text {,time }}{ }^{\mathrm{i}} \mathrm{P} \mathrm{CN}_{\mathrm{sg} \text {,time }}{ }^{\mathrm{i}}\right]_{\mathrm{Cx}}$ node.

The semi-specified level also helps the construction grammarian to show that the construction has certain lexical biases (not all prepositions and nouns are productive; see Figure 4). Speakers keep track of those statistical biases (Goldberg 2019; Hilpert 2014; Stefanowitsch and Gries 2003). Studies have shown that speakers retain a highly detailed record of linguistic usage events in memory. Similarly, we have also shown that the different prepositions attract different nouns. The postulation and concreteness of the lower levels in the network mirrors this psychological reality. Finally, the semi-specific level helps in modelling because it subsumes all the fully-specified constructions below it. This relates to another issue, which shall be discussed with the help of the day to day example.

\subsubsection{Peculiar daughters: the fully specified level}

In the case of day to day, we could argue that all the found examples are licensed by the $\left[\mathrm{CN}_{\mathrm{sg} \text {,time }}{ }^{\mathrm{i}} \text { to } \mathrm{CN}_{\mathrm{sg} \text {,time }}{ }^{\mathrm{i}}\right]_{\mathrm{Cx}}$ node. For instance, in example (28), where the NPN functions as an adjunct, the meaning of the construction can be described as from one day to the next day\}.

\section{Our customers are often living day to day or week to week (2011 NEWS USAToday)}

This semantic interpretation is supported by the fact that in 366 examples, day to day is preceded by the preposition from.

There's no consistency from day to day, or from paragraph to paragraph... (2000, MAG, NatlReview)

In all those cases, it is safe to assume that the construct is either licensed by the [(from) $\mathrm{CN}_{\mathrm{sg} \text {,time }}{ }^{\mathrm{i}}$ to $\left.\mathrm{CN}_{\mathrm{sg} \text {,time }}{ }^{\mathrm{i}}\right]_{\mathrm{Cx}}$ template or even another construction [from $\mathrm{N}$ to $\mathrm{N}]_{\mathrm{Cx}}$ (from January to March, from morning to evening, from paragraph to paragraph, from London to New York, ...) (Zwarts 2013).

However, in the following examples the meaning of day to day is very different:

(30) Davis is day to day, but Albright will miss the rest of the season (2010, NEWS, Atlanta) 
(31) my waist, curves, and cleavage! “ ” Here's how I dress day to day. It's youthful and not as done up, which is good (2008 MAG Cosmopolitan)

(32) The day to day that I was being raised with was a more universal approach to thinking (SPOK NPR: Fresh Air)

In example (30), day to day functions as a subject complement with the following semantics: \{unstable as a player\}. In example (31), day to day means \{every day/ daily\}. In example (32), day to day means \{daily routines\}, a semantic interpretation which is triggered by its usage as a nominal head in a noun phrase. In all these cases, it is necessary to postulate the existence of a polysemous, fully-specified [day to day] construction with very idiomatic behavior that is not inherited from the higher levels. This [day to day] construction - following the current conventions of $\mathrm{CxG}$ modelling - is positioned on the lowest level of the network (see Figure 5). In contrast, the from one day to the next day reading is the default and is stored in the $\left[\mathrm{CN}_{\mathrm{sg} \text {,time }} \mathrm{i}^{\mathrm{i}} \text { to } \mathrm{CN}_{\mathrm{sg} \text {,time }}{ }^{\mathrm{i}}\right]_{\mathrm{Cx}}$ node. ${ }^{23}$

Also, from a quantitative point of view we have good arguments for the existence of these low-level nodes. In our preposition-specific collostructional analysis (synthesized in the collostructional graph in Figure 4), we clearly see that for a given noun not all prepositions function as productive attractees. For example, even though [hour $\mathrm{P}$ hour] can be argued to have a mid-level node in the construction network (as argued in 4.1.1), there is no empirical evidence for a lowlevel node [hour on hour]. This is because hour and on do not show a robust attractor relationship in Figure 4. In contrast, hour and after (as well as by and upon, respectively), for example, do show such a relationship: within [hour P hour], after surfaces as preposition significantly more often than expected by chance. This renders the existence of such a low-level node plausible.

Note that again a diachronic aspect can be integrated here. It is quite plausible that these low-level constructions with their specific, non-compositional meaning developed later in time, ${ }^{24}$ after the establishment of other, more abstract templates. Thus, we can assume a case of network reconfiguration at one point, where new expressions are constantly added to the construction.

In a usage-based approach, following Goldberg's (2006) definition of what a construction is, also high frequency warrants the postulation of a separate node. As was already discussed in section 3, year after year or day after day despite being quite transparent and compositional in their meaning, deserve constructional

23 In a similar manner, we postulate the existence of other idiomatic, fully specified constructions like, [eye to eye $]_{\mathrm{Cx}}$ or $[\text { step by step }]_{\mathrm{Cx}}$ (see section 4.2 below).

24 This hypothesis will have to be tested in future diachronic studies. 
status as fully specified, frozen chunks on the lowest level due to their high frequency and attraction strength (see Figure 5).

\subsubsection{More complex templates: modification and complementation}

Let us now briefly return to the cases with modification and complementation.

Day after desperate day of unbroken siege passed. (COCA, 2006, MAG Military History)

In the introduction, we asked whether constructs as in example (33) should make us schematize the following template with optional modification slots: [(ADJ $\left.{ }_{\text {mod }}\right)$ $\mathrm{CN}_{\mathrm{sg} \text {,time }}{ }^{\mathrm{i}} \mathrm{P}\left(\mathrm{ADJ} \mathrm{J}_{\mathrm{mod}}\right) \mathrm{CN}_{\mathrm{sg} \text {,time }} \mathrm{i}^{\mathrm{i}}$ (of $\left.\left.\mathrm{X}_{\mathrm{compl}}\right)\right]_{\mathrm{Cx}}$. In other words, should all of our templates postulated so far be extended by these optional slots? We argue against this modeling strategy. The empirical analysis has shown that modification and complementation are very rare in NPN constructions (see section 3.2.3). Postulating optional modifier slots disregards the rather frozen character of the constructions. An extended template somehow suggests a high degree of compositionality which many of these constructions do no longer have. We believe that only in the case of after and perhaps upon and by, an additional extended schema makes sense. For example, something along the lines of $\left[\left(\mathrm{ADJ}_{\mathrm{mod}}\right) \mathrm{CN}_{\mathrm{sg} \text {,time }}\right.$ after $\left(\mathrm{ADJ}_{\text {mod }}\right) \mathrm{CN}_{\mathrm{sg} \text {,time }}$ i (of $\left.\left.\mathrm{X}_{\text {compl }}\right)\right]_{\mathrm{Cx}}$.

Related to this extended template, two open questions are left for future research. The first one would be how and if such a template is connected to and inherits from a default NP template $\left[\mathrm{DET}+\mathrm{ADJ}+\mathrm{N}+\right.$ Comp $_{\mathrm{Cx}}$. The second question relates to the scope of the adjective and how we can express that any modifier or complement is interpreted across the board, in the sense that every day is day of unbroken siege which is desperate.

\subsection{The larger NPN network: absent mothers but sister relations}

Although we cannot provide any large-scale empirical evidence at this point, we argue that the NPN family should be extended by several other templates, for example, the

$\left[\mathrm{CN}_{\mathrm{sg} \text {,measurement }}^{\mathrm{i}}\right.$ by $\left.\mathrm{CN}_{\mathrm{sg} \text {, measurement }}{ }^{\mathrm{i}}\right]$ construction (e.g., inch by inch, layer by layer) or the $\left[\mathrm{CN}_{\mathrm{sg} \text {,bodypart }}^{\mathrm{i}} \text { to } \mathrm{CN}_{\mathrm{sg} \text {,bodypart }}{ }^{\mathrm{i}}\right]_{\mathrm{Cx}}$ template (e.g., face to face, shoulder to shoulder).

These constructions account for the fact that very often body part nouns or measure nouns are recruited into the template (Jackendoff 2008; König and Moyse-Faurie 2009). Similarly to the temporal NPNs, speakers will ultimately 
also detect similarities between inch by inch and kilometer by kilometer or between skin to skin and shoulder to shoulder and schematize more general templates on a higher level like $\left[\mathrm{CN}_{\mathrm{sg} \text {,measurement }}^{\mathrm{i}}\right.$ by $\left.\mathrm{CN}_{\mathrm{sg} \text {,measurement }}{ }^{\mathrm{i}}\right]$ or $\left[\mathrm{CN}_{\mathrm{sg} \text {,bodypart }}{ }^{\mathrm{i}} \text { to } \mathrm{CN}_{\mathrm{sg} \text {,bodypart }}{ }^{\mathrm{i}}\right]_{\mathrm{Cx}}$. In many examples, the used common noun is an animate/inanimate bounded entity, object or thing. Constructs like government after government, student after student are thus licensed by an $\left[\mathrm{CN}_{\mathrm{sg} \text {,entity }}{ }^{\mathrm{i}}\right.$ after $\left.\mathrm{CN}_{\text {sg,entity }}{ }^{\mathrm{i}}\right]$ template (see Figure 6).

The different semantics of the used nouns in combination with the used prepositions leads to differences is the constructions' semantics. Whereas the constructions with measure nouns $\left[\mathrm{CN}_{\mathrm{sg} \text {,measurement }}^{\mathrm{i}}\right.$ after $\left.\mathrm{CN}_{\mathrm{sg} \text {,measurement }}{ }^{\mathrm{i}}\right]$ are very similar to the one with temporal nouns and expresses iiterated succession/ accumulation of measurement unit\}, the prime meaning of $\left[\mathrm{CN}_{\text {sg,entity }}\right.$ i upon $\mathrm{CN}_{\text {sg,entity }}{ }^{\mathrm{i}}$ ] seems to be \{quantification, accumulation or some kind of stacking\} as in brick upon brick. The body part template is the most complex one. Body parts in combination with the preposition to either expresses \{juxtaposition\} or \{spatial opposition\} e.g., skin to skin or face to face. Interestingly, in combination with body parts, to never has the meaning of succession. We assume that all these subconstructions are warranted for the same reasons that were mentioned in 4.1. The templates show slightly different semantics based on their prepositions and their used nouns. Obviously, their specific linguistic behavior (productivity, frequency, etc.) will have to be investigated empirically in the future. These templates can be seen as sister nodes to each other.

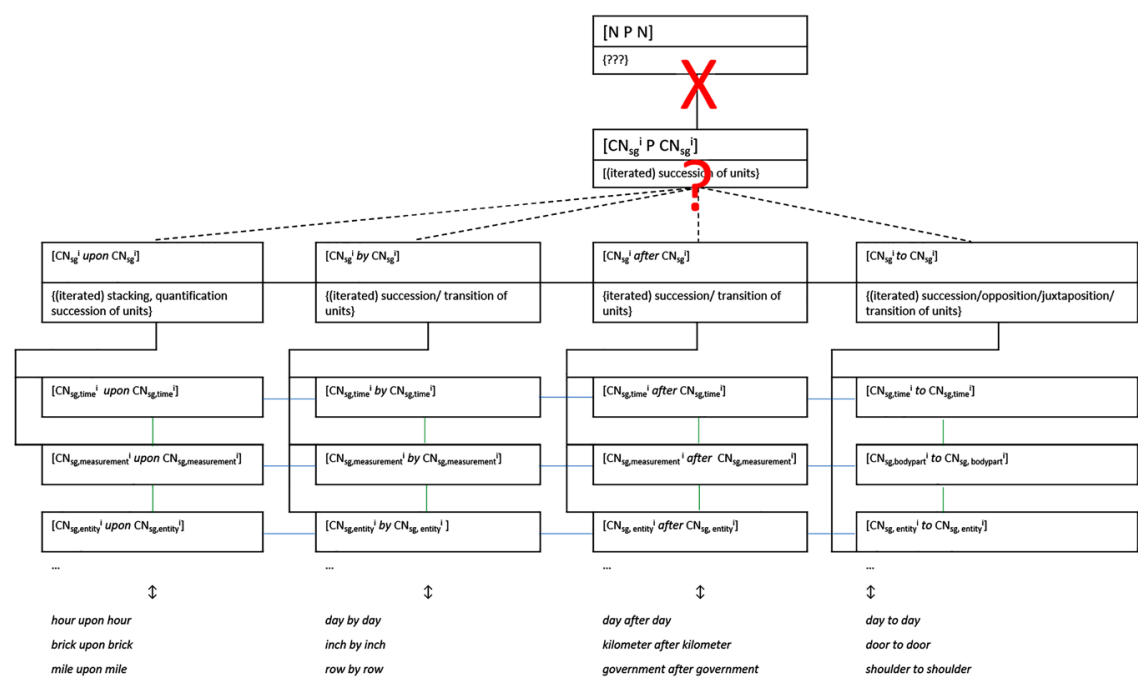

Figure 6: Partial network sketch of NPN constructions. 
We have tried to sketch all these complex relations in Figure 6. Again, keep in mind that Figure 6 is a partial sketch as only four prepositional types are sketched. Moreover, the semantic pole of the lower templates was not added. Also, this figure does not show all the assumed sub-nodes nor all assumed horizontal links on the lower levels. For example, idiomatic expressions like [see eye to eye] $\leftrightarrow$ in agreement with someone $\}$ or [face to face] $\leftrightarrow$ in person $\}$ would deserve their own node on a lower level. Blue and green lines both indicate horizontal connections. It is assumed that $\left[\mathrm{CN}_{\mathrm{sg} \text {,measurement }}^{\mathrm{i}}\right.$ after $\left.\mathrm{CN}_{\mathrm{sg} \text {,measurement }}{ }^{\mathrm{i}}\right],\left[\mathrm{CN}_{\mathrm{sg} \text {,time }}{ }^{\mathrm{i}}\right.$ after $\mathrm{CN}_{\mathrm{sg}, \mathrm{ti}-}$ $\left.{ }_{\mathrm{me}}^{\mathrm{i}}\right]_{\mathrm{Cx}}$ and $\left[\mathrm{CN}_{\mathrm{sg} \text {,entity }}{ }^{\mathrm{i}} \text { after } \mathrm{CN}_{\mathrm{sg} \text {,entity }}{ }^{\mathrm{i}}\right]_{\mathrm{Cx}}$ are sisters to each other even if they are positioned below each other. However, limited space and the chosen twodimensional network design does not allow for a better alternative visualization. At the same time, we also assume horizontal links between $\left[\mathrm{CN}_{\mathrm{sg} \text {,time }}{ }^{\mathrm{i}}\right.$ after $\left.\mathrm{CN}_{\mathrm{sg} \text {,time }}{ }^{\mathrm{i}}\right]_{\mathrm{Cx}}$ and $\left[\mathrm{CN}_{\mathrm{sg} \text {,time }}{ }^{\mathrm{i}} \text { to } \mathrm{CN}_{\mathrm{sg} \text {,time }}{ }^{\mathrm{i}}\right]_{\mathrm{Cx}}$ etc (see Figure 5). So, the individual templates are connected in more than one way. Only black lines are vertical inheritance links.

We argue that in this extended NPN network, speakers abstract to a higher semi-specified level at which the prepositions are still specific but the noun slot is basically semantically open (with the limitation of being singular and identical), e.g., $\left[\mathrm{CN}_{\mathrm{sg}}{ }^{\mathrm{i}}\right.$ after $\left.\mathrm{CN}_{\mathrm{sg}}{ }^{\mathrm{i}}\right]$ or $\left[\mathrm{CN}_{\mathrm{sg}}{ }^{\mathrm{i}}\right.$ to $\left.\mathrm{CN}_{\mathrm{sg}}{ }^{\mathrm{i}}\right]$. This is very similar to what Jackendoff does in his 2008 paper where he also acknowledges the differences between the various prepositions. For Jackendoff, it is the prepositions' semantics which primarily distinguishes the templates, not so much the meaning of the various nouns in it.

If we assume this level, the next question is if speakers abstract to any higher nodes. Here we deviate from Jackendoff (2008) or Jackendoff and Audring (2019) in our line of argumentation. Jackendoff argues that the speakers abstract to a higher level like $\left[\mathrm{CN}_{\mathrm{sg}}{ }^{\mathrm{i}} \mathrm{P} \mathrm{CN}{ }_{\mathrm{sg}}{ }^{\mathrm{i}}\right]_{\mathrm{Cx}}$ or even $[\mathrm{N} \mathrm{P} \mathrm{N}]_{\mathrm{Cx} \text {. }}$ (2008: 17). Jackendoff explains that it is mostly the formal word order that the constructs inherit from these higher levels. He opts for this modelling solution because (a) he has nothing against schemas which are postulated on purely formal grounds and (b) because such abstract schemas allow him to connect the discussed symmetric NPs to non-symmetric NPNs and NPNs with proper nouns or plural nouns or many other related NPN types. A general NPN template can license strings like boy to girl, Christmas to New Year or rags to riches where the noun no longer is identical nor singular.

We find this problematic for various reasons. First of all, we argue that in UCCxG only meaningful constructions should be postulated. As Hilpert states, "purely formal generalizations, that is constructions without meaning, have no natural place in the construct-i-con" (Hilpert 2014: 57). We are aware that some construction grammarians accept schematization over formal similarities but we simply do not subscribe to such an approach. Schematization and abstraction are 
ultimately based on the recognition of (primarily semantic and functional) similarities. Admittedly, it is possible to argue that the prototypical overarching meaning of the $\left[\mathrm{CN}_{\mathrm{sg}}{ }^{\mathrm{i}} \mathrm{P} \mathrm{CN}_{\mathrm{sg}}{ }^{\mathrm{i}}\right]_{\mathrm{Cx}}$ construction can be described as some kind of \{succession, accumulation or quantification\} but where is the added value to this node, especially if we know that not all prepositions are productive in the slot (see similar discussion in 4.1).

We are not at all against the postulation of abstract 'prototypical meanings' or against abstract nodes in general but only when and where it is warranted. For example, if you have definite NP constructions like [POSS $+\mathrm{CN}]$ or [DEM $+\mathrm{CN}]$ where thousands of strings show uniform behavior and which are truly fully productive (no lexical biases/restrictions) then we suggest that a higher-level [DET $+\mathrm{CN}]$ likely emerges which is highly abstract and has a procedural discoursepragmatic albeit rather vague meaning (namely marking indefiniteness). In other words, in many cases we agree that nodes high up exist (e.g., the ditransitive construction). However, for us highly abstract nodes are very productive templates which express procedural coding (i.e., general grammatical rules) that is no longer limited to certain semantic classes or which shows little genre biases.

Even if one can see any good arguments for the postulation of an $\left[\mathrm{CN}_{\mathrm{sg}}{ }^{\mathrm{i}} \mathrm{P}\right.$ $\left.\mathrm{CN}_{\mathrm{sg}}{ }^{\mathrm{i}}\right]_{\mathrm{Cx}}$ node, we do not at all see any level higher than that. The often-used term NPN, which linguists employ to write about this constructional family, is a fiction in the sense that there is no corresponding [N P N] schema to be found. The requirement that the nouns are singular and identical is far too crucial. Only if the nouns are identical a certain semantic reading of succession/quantification is created. A general NPN string would subsume all kinds of binominal strings box of chocolates, sort of cake, road under construction, boy to man or April to May. These are only formally similar in nature and there is no underlying shared meaning whatsoever.

We argue that in the case of NPNs the family is too restricted in various ways and it is not necessary to postulate mothers extremely high up. Why not dare to stay on the lower levels if the constructional architecture allows us to do so. Thus, we conclude that this NPN family is one of those families where the local architecture of the network 'works' without a highly abstract level. Several sister constructions exist; they are 'strong' in the sense that they are the ones responsible for licensing utterances, instead of their mothers.

\section{Conclusion}

NPN constructions are an interesting target of analysis. The empirical analysis has revealed that the various family members differ in their semantics and are 
more or less compositional, idiomatic, frequent and productive. The templates have different collostructional preferences. From our point of view, these differences and semi-productivity warrants the postulation of many individual fully specified or semi-specified constructional nodes. At the same time, it was shown that many NPNs do not have modification/complementation potential which confirms their frozen character. By providing a large scale quantitative empirical analysis of the NPN family, we have contributed to ongoing research by offering important information about frequency and productivity. On a metatheoretical level, we have tried to shed light on the question when it is warranted to postulate the existence of a separate node in a usage-based constructional model. Here, we have concluded that the NPN family consists of many peculiar daughters and many sister relations. Moreover, we have tried to discuss the plausibility of mother nodes. Although we are not per se against the postulation of abstract mother nodes, we believe that this family is a case where we better do without them.

Discussing this constructional group has hopefully helped to tackle some open questions in UCCxG but it has also led to new challenges especially when drawing network sketches. As was shown, sketching even the network part for the subfamily with temporal nouns is already extremely complex. On the one hand, there is the need to postulate many fully specified constructions like [day to day $]_{\mathrm{Cx}}$ or [year after year $]_{\mathrm{Cx}}$. On the other hand, the two-dimensional network structure does not do justice to the complexity of the assumed connections. For example, some subtypes (e.g., the one with after) exhibit special behavior (modification, complementation, collocation with the preposition from), which suggests the existence of additional templates. Another open question is how the postulated templates are connected to other strings with similar meaning and/or form like e.g., [from one $\mathrm{CN}_{\mathrm{sg} \text {,time }}$ to the next], [one $\mathrm{CN}_{\mathrm{sg} \text {,time }}$ after the other]. This relates to the phenomenon of Multiple Inheritance (Croft 2001; Goldberg 1995) and the question how the NPN family and its various templates may not only inherit information from one but several different abstract mothers.

Also, the annotation of all examples revealed that in approximately $10 \%$ of the examples we find interesting multiplication patterns like in (a) night after night after night after night - I kept seeing their faces (COCA, 2001, DPOK, NBC_Dateline). Often the NPN string gets multiplied or different NPNs cluster, e.g., Live with that minute after minute, hour after hour, day after day, week after week (COCA, 1997, SPOK, NBC. Today). We assume that speakers combine NPNs in this way for discourse-pragmatic, stylistic reasons but also cognitive priming may be an issue here. An open question is which constructional templates license such utterances? Unfortunately, a discussion of such strings goes beyond the scope of this paper. For a 
more detailed analysis of multiplication patterns, stylistic clustering/sequencing as well as the distribution of syntactic functions see Sommerer (accepted).

Even if many questions are left unanswered and there is need for further research, we believe that the NPN family is best described in a model of grammar with no strict separation between lexicon and grammar which knows how to integrate semi-idiomaticity and semi-productivity and which can account for lexical biases. A model which is flexible in its architecture (postulating higher nodes only when warranted) should be favored over a model which does not, because it is cognitively more realistic.

\section{References}

Beck, Sigrid \& Arnim Von Stechow. 2006. Dog after dog revisited. Proceedings of the Sinn und Bedeutung 10. 43-54.

Blumenthal-Dramé, Alice. 2012. Entrenchment in usage-based theories. What corpus data do and do not reveal about the mind. Berlin: Walter de Gruyter.

Bybee, Joan. 2010. Language, usage and cognition. Cambridge \& New York: Cambridge University Press.

Cappelle, Bert. 2006. Particle placement and the case for "allostructions". Constructions Online SVI-7. 1-28.

Croft, William. 2001. Radical construction grammar: Syntactic theory in typological perspective. Oxford: Oxford University Press.

Croft, William \& Allen Cruse. 2004. Cognitive linguistics. Cambridge: Cambridge University Press. Culicover, Peter W. 1999. Syntactic nuts: Hard cases in syntax. Oxford: Oxford University Press.

Culicover, Peter W. \& Ray Jackendoff. 2005. Simpler syntax. New York: Oxford University Press.

Dabrowska, Ewa. 2012. Different speakers, different grammars: Individual differences in native language attainment. Linguistic Approaches to Bilingualism 2(3). 219-253.

Davies, Mark. 2008-. The Corpus of Contemporary American English (COCA): 570 million words, 1990-present. http://corpus.byu.edu/coca/.

Diessel, Holger. 2011. Review of “Language, usage and cognition” by Joan Bybee. Language 87. 830-844.

Diessel, Holger. 2015. Usage-based construction grammar. In Ewa Dąbrowska \& Dagmar Divjak (eds.), Handbook of cognitive linguistics, 295-321. Berlin: Mouton de Gruyter.

Diessel, Holger. 2019. The grammar network. How linguistic structure is shaped by language use. Cambridge: Cambridge University Press.

Diessel, Holger \& Martin Hilpert. 2016. Frequency effects in grammar. In Mark Aronoff (ed.), Oxford research encyclopedia of linguistics. Oxford: Oxford University Press. http://www. personal.uni-jena.de/ x4diho/Frequency\%20effects\%20in\%20grammar.pdf (accessed 06 April 2018).

Divjak, Dagmar. 2008. On (in)frequency and (un)acceptability. In Barbara Lewandowska-Tomaszczyk (ed.), Corpus linguistics, computer tools and applications - State of the art, 213-233. Frankfurt: Peter Lang. 
Divjak, Dagmar. 2019. Frequency in language. Memory, attention and learning. Cambridge: Cambridge University Press.

Ellis, Nick C., Ute Römer \& Mathew B. O’Donnell. 2016. Usage-based approaches to language acquisition and processing: Cognitive and corpus investigations of construction grammar (Language Learning Monograph Series 66). Malden, MA: Wiley-Blackwell.

Fillmore, Charles J., Paul Kay \& Mary C. O'Connor. 1988. Regularity and idiomaticity in grammatical constructions: The case of let alone. Language 64. 501-538.

Goldberg, Adele E. 1995. Constructions: A construction grammar approach to argument structure. Chicago: University of Chicago Press.

Goldberg, Adele E. 2003. Constructions: A new theoretical approach to language. Trends in Cognitive Sciences 7(5). 219-224.

Goldberg, Adele E. 2006. Constructions at work: The nature of generalization in language. Oxford: Oxford University Press.

Goldberg, Adele E. 2013. Constructionist approaches to language. In Thomas Hoffmann \& Graeme Trousdale (eds.), The Oxford handbook of construction grammar, 15-31. Oxford: Oxford University Press.

Goldberg, Adele E. 2019. Explain me this. Creativity, competition, and the partial productivity of constructions. Princeton New Jersey: Princeton University Press.

Haïk, Isabelle. 2009. Symmetric structures. Corela 11(1). https://journals.openedition.org/ corela/2875 (accessed 02 March 2019).

Heycock, Caroline \& Roberto Zamparelli. 2003. Coordinated bare definites. Linguistic Inquiry 34. 443-469.

Hoffmann, Thomas \& Graeme Trousdale (eds.). 2013. The Oxford handbook of construction grammar. Oxford: Oxford University Press.

Hilpert, Martin. 2014. Construction grammar and its application to English. Edinburgh: Edinburgh University Press.

Hilpert, Martin \& Holger Diessel. 2016. Entrenchment in construction grammar. In Hans-Jörg Schmid (ed.), Entrenchment and the psychology of language learning, 57-74. Berlin: Mouton de Gruyter.

Jackendoff, Ray. 2008. Construction after construction' and its theoretical challenges. Language: Journal of the Linguistics Society of America 84(1). 8-28.

Jackendoff, Ray. 2013. Constructions in the parallel architecture. In Thomas Hoffmann \& Graeme Trousdale (eds.), The Oxford handbook of construction grammar, 70-92. Oxford: Oxford University Press.

Jackendoff, Ray \& Jenny Audring. 2019. The texture of the lexicon. Relational morphology and the parallel architecture. Oxford: Oxford University Press.

Kim, Jong-Bok \& Peter Sells. 2015. English binominal NPs: A construction-based perspective. Journal of Linguistics 51(1). 41-73.

König, Ekkehard \& Claire Moyse-Faurie. 2009. Spatial reciprocity: Between grammar and lexis. In Johannes Helmbrecht, Yoko Nishina, Yong-Min Shin, Stavros Skopeteas \& Elisabeth Verhoeven (eds.), Form and function in language research: Papers in honour of Christian Lehmann, 57-68. New York: Mouton de Gruyter.

Matsuyama, Tetsuya. 2004. The $\mathrm{N}$ after $\mathrm{N}$ construction: a constructional idiom. English Linguistics. Journal of English Linguistics Society of Japan 21. 55-84.

Matsuyama, Tetsuya. 2006. A note of the two-sided behavior of N after N. English Linguistics. Journal of English Linguistics Society of Japan 23(2). 446-453. 
Payne, John \& Rodney Huddleston. 2002. Nouns and noun phrases. In Rodney Huddleston \& Geoffrey K. Pullum (eds.), The Cambridge grammar of the english language, 323-523. Cambridge: Cambridge University Press.

Perek, Florent. 2015. Argument structure in usage-based construction grammar: Experimental and corpus-based perspectives. Amsterdam: John Benjamins.

Pskit, Wiktor. 2015. The categorial status and internal structure of NPN forms in English and Polish. In Prazmowska Anna \& Bondaruk Anna (eds.), Within language, beyond theories (Volume I): Studies in theoretical linguistics, 27-42. Newcastle upon Tyne: Cambridge Scholars Publishing.

Pskit, Wiktor. 2017. Linguistic and philosophical approach to NPN structures. In Wiktor Pskit (ed.), Topics in syntax and semantics: Linguistic and philosophical perspectives, 93-128. tódź: Wydawnictwo Uniwersytetu tódzkiego.

Quirk, Randolph, Sidney Greenbaum, Geoffrey Leech \& Jan Svartvik. 1985. A Comprehensive grammar of the English language. London: Longman.

Schmid, Hans-Jörg. 2010. Does frequency in text really instantiate entrenchment in the cognitive system? In Dylan Glynn \& Kerstin Fischer (eds.), Quantitative methods in cognitive semantics: Corpus-driven approaches, 101-133. Berlin: De Gruyter Mouton.

Schmid, Hans-Jörg \& Helmut Küchenhoff. 2013. Collostructional analysis and other ways of measuring lexicogrammatical attraction: Theoretical premises, practical problems and cognitive underpinnings. Cognitive Linguistics 24(3). 531-577.

Smirnova, Elena \& Lotte Sommerer. 2020. The nature of the node and the network: open questions in diachronic construction grammar. In Lotte Sommerer \& Elena Smirnova (eds.), Nodes and networks in diachronic construction grammar (Constructional Approaches to Language 27), 1-42. Amsterdam: John Benjamins.

Sommerer, Lotte. 2018. Article emergence in Old English. A constructionalist perspective. Berlin \& Boston: De Gruyter Mouton.

Sommerer, Lotte. Accepted. Day to day and night after night: temporal NPN constructions in English. In Lotte Sommerer \& Evelien Keizer (eds.), English noun phrases from a functionalcognitive perspective: current issues (Studies in language companion series). Amsterdam: John Benjamins.

Sommerer, Elena \& Lotte Smirnova (eds.). 2020. Nodes and networks in diachronic construction grammar. Amsterdam: John Benjamins.

Stefanowtisch, Anatol. 2006. Negative evidence and the raw frequency fallacy. Corpus Linguistics and Lingistic Theory 2(1). 61-77.

Stefanowitsch, Anatol. 2013. Collostructional analysis. In Graeme Trousdale \& Thomas Hoffmann (eds.), The Oxford handbook of construction grammar, 290-306. Oxford: Oxford University Press.

Stefanowitsch, Anatol \& Stefan Th. Gries. 2003. Collostructions: Investigating the interaction of words and constructions. International Journal of Corpus Linguistics 8(2). 209-243.

Tomasello, Michael. 2003. Constructing a language: $A$ usage-based theory of language acquisition. Cambridge, MA: Harvard University Press.

Travis, Lisa. 2001. The syntax of reduplication. Proceedings of NELS 31. 455-469.

Travis, Lisa. 2003. Reduplication feeding syntactic movement. In S. Somesfalean (ed.), Proceedings of the 2003 Canadian Linguistic Association Annual Conference, 236-247. Montréal: Département de linguistique et de didactique des langues, Université du Québec à Montréal. 
Van de Velde, Freek. 2014. Degeneracy: The maintenance of constructional networks. In Ronny Boogaart, Timothy Colleman \& Gijsbert Rutten (eds.), Extending the scope of construction grammar, 141-179. Berlin: De Gruyter Mouton.

Zehentner, Eva. 2019. Competition in language change: The rise of the English dative alternation. Berlin \& Boston: De Gruyter Mouton.

Zwarts, Joost. 2013. From N to N: The anatomy of a construction. Linguistics and Philosophy 36(1). 65-90.

Supplementary Material: The online version of this article offers supplementary material (https:// doi.org/10.1515/cog-2020-0013). 